Article

\title{
Remote Sensing of Spatiotemporal Changes in
} Wetland Geomorphology Based on Type 2 Fuzzy Sets: A Case Study of Beidagang Wetland from 1975 to 2015

\author{
Hongyuan Huo ${ }^{1}$, Jifa Guo ${ }^{2, *}$, Zhao-Liang $\mathrm{Li}^{1,3}$ and Xiaoguang Jiang ${ }^{4}$ \\ 1 Key Laboratory of Agricultural Remote Sensing, Ministry of Agriculture/Institute of Agricultural Resources \\ and Regional Planning, Chinese Agricultural Academy of Sciences, Beijing 100081, China; \\ hongyuanh@gmail.com (H.H.); lizl@unistra.fr (Z.-L.L.) \\ 2 College of Urban and Environmental Sciences, Tianjin Key Laboratory of Water Resources and Environment, \\ Tianjin Normal University, Tianjin 300387, China \\ 3 ICube, CNRS, Université de Strasbourg, 300 Boulevard Sébastien Brant, CS10413, 67412 Illkirch, France \\ 4 College of Resources and Environment, University of Chinese Academy of Sciences, Beijing 100049, China; \\ xgjiang@aoe.ac.cn \\ * Correspondence: guojifa@mail.tjnu.edu.cn; Tel.: +86-022-23766313
}

Academic Editors: Deepak R. Mishra and Prasad S. Thenkabail

Received: 9 May 2017; Accepted: 29 June 2017; Published: 4 July 2017

\begin{abstract}
Few studies have considered the spatiotemporal changes in wetland land cover based on type 2 fuzzy sets using long-term series of remotely sensed data. This paper presents an improved interval type 2 fuzzy c-means (IT2FCM ${ }^{*}$ ) approach to analyse the spatial and temporal changes in the geomorphology of the Beidagang wetland in North China from 1975 to 2015 based on long-term Landsat data. Unlike traditional type 1 fuzzy c-means methods, the IT2FCM* algorithm based on interval type-2 fuzzy set has an ability to better handle the spectral uncertainty. Four indexes were adopted to validate the separability of classes with the IT2FCM* algorithm. These four validity indexes showed that IT2FCM ${ }^{*}$ obtained better results than traditional methods. Additionally, the accuracy of the classification results was assessed based on the confusion matrix and kappa coefficient, which were high for the analysis of wetland landscape changes. Based on the analysis of separability of classes with the IT2FCM ${ }^{*}$ algorithm using four validity indexes, the classification results, and the membership value images, the long-term series of satellite datasets were processed using the IT2 $\mathrm{FCM}^{*}$ method, and the study area was classified into six classes. Because water resources and vegetation are two key wetland components, the water resource dynamics and vegetation dynamics, based on the normalized difference vegetation index (NDVI), were analysed in detail according to the spatiotemporal classification results. The results show that the changes in vegetation types have historically been associated with water resource variations and that water resources play an important role in the evolution of vegetation types.
\end{abstract}

Keywords: Landsat; wetland; fuzzy clustering; spatiotemporal changes; type-2 fuzzy set

\section{Introduction}

The official federal definition of wetlands was provided by Cowardin et al. [1] as follows: "Wetlands are transitional lands between terrestrial and aquatic systems where the water table is usually at or near the surface or the land is covered by shallow water". Wetlands are considered an immensely important part of the global ecosystem and support high levels of biodiversity, including significant numbers of rare and endangered plant and animal species [2,3], although they only cover approximately $6 \%$ of the Earth's land surface [4,5]. Wetlands also provide flood protection, protection from storm and wave damage, water quality improvements through the filtering of agricultural 
and industrial waste, and aquifer recharge [6-8]. Although wetlands play an important role in environmental processes and provide many ecological services for mankind, they are under increasing threats from climate change, dredge and fill operations, hydrologic variations, pollutant runoff, eutrophication, impoundments, and land modification, as well as the growing load placed on wetlands by agriculture, aquaculture, forestry, and development [9-13].

To better conserve and manage wetland resources, it is important to inventory and monitor wetlands and their adjacent uplands. Photographic evidence of hydrological conditions, in combination with collateral data, is sufficient to accurately document wetland existence. Recently, with the rapid development of image processing techniques, wetland resources monitoring and corresponding land cover changes based on satellite remote sensing has displayed considerable advantages over other traditional methods, especially over large geographic areas. Many clustering algorithms and methods for land cover classification have been proposed based on remotely sensed datasets with different spatial and spectral resolutions, such as NOAA AVHRR, Terra MODIS and ASTER, Landsat TM/ETM+, and EO-1 Hyperion and ALI, as well as airborne remote sensing datasets, including AVIRIS, HyMap, and others [14-20]. Compared with traditional Boolean classification methods, clustering algorithms based on fuzzy sets are more appropriate for land cover mapping [21-23].

Fuzzy c-means (FCM) clustering is an important image classification algorithm and is widely used in remote sensing image analysis. In image segmentation, a record in a fuzzy classification reflects the degree to which any object belongs to all candidate classes [24]. Thus, the outcome of a fuzzy classification is a record for every object being analysed of the degree to which that object belongs to every class being considered. In contrast, a Boolean classification simply records that an object either is (1) or is not (0) part of the set. Typically, this is done by recording only the set to which each object belongs. Therefore, in land cover classification, for any pixel or object under consideration, a Boolean classification might simply record that the pixel or object belongs to the class grassland among a set of five classes [grassland, woodland, grass land, bare soil, water], while a fuzzy classification might record a list of the degree of membership of each class, e.g., [0.5, 0.2, 0.2, 0.1, 0]. It is not required that the membership degrees should sum to 1, but this is a common restriction of fuzzy classification [23].

The original clustering algorithms, such as k-means, fuzzy c-means (FCM), and kernel fuzzy c-means, are all type 1 FCM methods, and most use Euclidean distance to quantify the degree of similarity between data points and the corresponding membership degree $[23,25,26]$. FCM with spatial information has been applied to enhance segmentation algorithms for use with remotely sensed imagery containing noise $[27,28]$. Shao et al. proposed a novel and robust semi-supervised FCM (RSFCM) clustering method to detect more changes than traditional methods and provide noise immunity by synergistic exploitation of pseudo-labels based on a difference image and spatial information [26]. Wang et al. proposed an adaptive spatial-information-based fuzzy clustering algorithm for image segmentation that overcomes the sensitivity to noisy information and the lack of spatial information, which improved the robustness of traditional FCM methods [29].

Since type-1 fuzzy set theory was first introduced in [29], conventional type 1 FCM methods such as k-means and FCM have been developed and applied to many domains due to their ability to model fuzziness. However, the classical FCM clustering methods are based on type- 1 fuzzy set theory, which cannot address uncertainties associated with membership grade; they do not perform well on data with complicated geometry, and they are unable to handle and quantify uncertainty when determining the associated membership function [30]. This fault can be overcome using the type-2 fuzzy set and the type-N fuzzy set introduced by Zadeh (1975) [31]. The type-2 fuzzy set is an extension of the type- 1 fuzzy set that makes computation extremely difficult, and it is also difficult to handle the secondary membership value or function. The interval type-2 fuzzy set (IT2 FS) is a special case of the type-2 fuzzy set for which the secondary membership grade is a constant equal to one (Mendel et al., 2002) [32]; consequently, it requires less computation than the type-1 fuzzy set and has been adopted in many domains [33]. In contrast, type 2 fuzzy sets have unique advantages and can be used to assess the uncertainty that exists in image data due to environmental factors such 
as weather conditions and sensor issues. Thus, these methods are used in data clustering, such as via the interval type 2 FCM clustering algorithm. A boosted genetic fuzzy classifier (BGFC) was developed by Stavrakoudis et al. for land cover classification using multispectral remote sensing data [34]. In this method, the fuzzy rules are generated in an iterative fashion, and a genetic tuning stage is also adopted to improve the cooperation among the fuzzy rules. The classification results of this method are generally good. Ghaffarian developed an automatic FCM algorithm based on a histogram of land cover classification and multispectral data [35]. Ghosh performed supervised change detection using fuzzy clustering combined with the spatial correlation between neighbouring pixels in a difference image, which was calculated from two images of the same location at different times [36]. In the standard FCM method, two parameters that can be set by users are the class number, $\mathrm{C}$, and the fuzzifier, $\mathrm{m}$ [36]. The cluster centres are expressed by real number vectors, and the distance between a sample and the cluster centres is used to determine the membership degree of a sample belonging to one class. As mentioned before, classical FCM clustering methods cannot handle the uncertainty of membership degree. An interval type 2 fuzzy c means (IT2FCM) was proposed in [33] based on the IT2 FS to handle fuzziness uncertainty in fuzzy clustering tests.

Until recently, however, very few studies have focused on land cover and land use based on IT2FS methods, and there are almost no studies regarding the use of such methods in spatiotemporal analyses of wetland dynamics. Thus, the first objective of this paper is to develop a study of wetland land cover change analysis based on the interval type-2 fuzzy set. Notably, the spectrum of a geographic feature does not refer to a single spectral curve but rather to a connected set of possible spectral curves, namely, a spectral curve with a certain width. The existing IT2FCM method does not take the width of a band into account; instead, it typically uses the ranks of the average values of lower and upper membership grades to determine whether the considered pixel belongs to a specific class. Moreover, the interval number ranking based on probability is never considered. Hence, the second objective of is to propose an approach that incorporates the interval number distance and ranking methods into IT2FCM. The method is called IT2FCM ${ }^{*}$, and it reflects the uncertainty in remotely sensed data [37]. Additionally, although many researchers have used the clustering validity indexes of the classical FCM algorithm, four extended cluster validity indexes are adopted in this paper: the partition coefficient (PC-), the partition entropy (PE-), the Fukuyama and Sugeno index (FS-), and the Xie and Beni index (XB-). Finally, based on IT2FCM* ${ }^{*}$, the spatial and temporal changes (from 1975 to 2015) in the Beidagang wetland, North China, are analysed based on a long-term series of Landsat satellite data. Three important factors indicating wetland geomorphology changes are introduced to the spatiotemporal analysis: water area, vegetation index, and vegetation types. Water plays a key role in wetlands. Thus, monitoring the changes in water areas is very important for the wetland. Aquatic vegetation in a wetland not only plays an important role in water purification by directly uptaking and utilizing nutrients in wastewater and absorbing heavy metals and other hazardous substances that accumulate in sewage but also enhances the capacity for the absorption and storage of carbon dioxide in the ecosystem through carbon sequestration. Thus, it is also very important for environmental wetland research to monitor the growth conditions of aquatic vegetation and their changes and evolution.

\section{Study Area}

This research was performed in the study area of Tianjin Municipality, a metropolis located in northern coastal China (see Figure 1a) with a latitude ranging from $38^{\circ} 34^{\prime}$ to $40^{\circ} 15^{\prime} \mathrm{N}$ and a longitude ranging from $116^{\circ} 43^{\prime}$ to $118^{\circ} 04^{\prime} \mathrm{E}$, covering an area of $11,860.63$ square $\mathrm{km}$ (4579.41 square miles). Tianjin is located along the west coast of the Bohai Sea (the West Pacific), and it is the largest coastal city in northern China. There are $153 \mathrm{~km}$ (95 miles) of coastline and $1137.48 \mathrm{~km}$ (706.80 miles) of land border. Tianjin is divided into 16 county-level divisions, all of which are districts (see Figure $1 \mathrm{~b}$ ) with a typical East Asian monsoon-influenced climate with windy and dry winters and hot and humid summers. The monthly 24 -h average temperature ranges from $-3.4{ }^{\circ} \mathrm{C}$ in January to $26.8^{\circ} \mathrm{C}$ in July, with an 
annual mean of $12.90^{\circ} \mathrm{C}$. Annual precipitation averages only $511 \mathrm{~mm}$, of which nearly three-fifths occurs in July and August, and annual evaporation totals $1120.5 \mathrm{~mm}$. Thus, the city lies within a semi-arid zone [38].

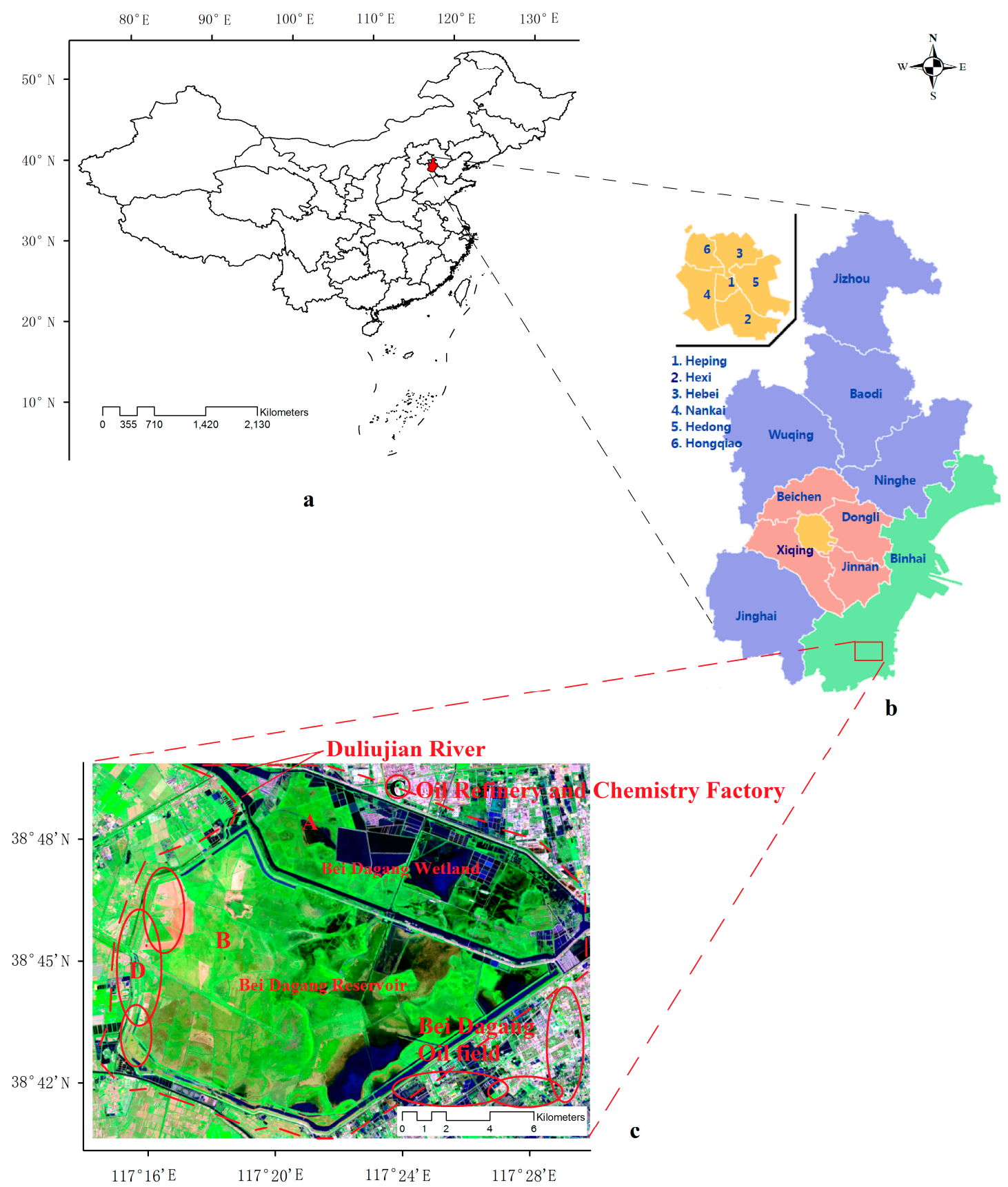

Figure 1. Study area of Tianjin Municipality, North China: (a) the location of Tianjin in China; (b) the location of the study area in Tianjin; and (c) the remotely sensed image obtained by the Landsat 8 satellite (acquired on 2 October 2015) with 7/5/3 bands in the RGB composite colour image.

The wetland area covered 5471 square $\mathrm{km}$ in Tianjin in the $1820 \mathrm{~s}$, accounting for $45.9 \%$ of the total area of the city. However, the area of natural wetland had decreased to $3.6 \%$ in 2000. This represents a $54.7 \%$ reduction in natural wetland area compared with that in the 1950s, and the urban wetland area decreased by $80 \%$ [39]. Even worse, this decreasing trend continues. In this context, the variation in the wetland area in Tianjin District has been studied. Dahuangpu, Beidagang and Qilihai are 
the main parts of the wetland in Tianjin. Among them, Dahuangpu has been the most severely affected by humans; its ecological value has decreased significantly as a result of the excavation of large areas of fishponds. In this research, the Beidagang wetland is selected as the study area due to its provincial significance regarding local climate conditions, its suitable size and the availability of moderate-resolution Landsat satellite data in the area. This area includes three or more wetland types (see Figure 1c). There are no clear boundaries between marshes and reservoirs, and wet areas frequently vary between each classification in the Beidagang wetland. Thus, both the Beidagang wetland and the Beidagang Reservoir were studied.

The soil of Beidagang is mainly composed of low-lying silt produced due to epeirogenesis (the formation and submergence of continents by broad, relatively slow displacements of the earth's crust) of the seacoast. With many crisscrossing rivers and ponds and abundant groundwater resources, the Beidagang wetland mainly includes five types of land cover types: lakes, beaches, marshes, rivers, and shallow sea areas. These land cover types encompass numerous ecosystem and biological resources. Notably, six types of first-class nationally protected birds and seventeen types of second-class nationally protected birds inhabit these areas. The wading bird population, which includes some endangered birds, can reach nearly eight million each year [39].

\section{Datasets and Preprocessing}

In this paper, three types of remotely sensed datasets are used, including the Advanced Land Imager (ALI) onboard the Earth Observation (EO-1) Mission, the multi-spectral scanner onboard the Sentinel-2 and the long-time series of Landsat datasets. The climate datasets for 22 August 2015 and 28 August 2016 in the study area were freely collected through the China Meteorological Administrative official website [40]. This climate dataset was used in combination with the Second Simulation of the Satellite Signal in the Solar Spectrum (6S) software to remove the atmospheric effects for the ALI and the Sentinel-2 datasets. In addition, the field survey dataset was collected on 27 June 2016 in the study area and its surrounding areas. The EO-1 ALI, Sentinel-2, and Landsat 8 satellite datasets were used to carry out an experiment to test the separability of the improved IT2FCM ${ }^{*}$ algorithm. The long-time series of Landsat satellite datasets were used to make the spatiotemporal analysis of wetland cover changes. The acquisition and preprocessing of these datasets are depicted in the following section.

\subsection{EO-1 ALI Dataset}

The multi-spectral dataset acquired on 22 August 2015 collected from the ALI instrument onboard the EO-1 satellite was used in this paper. The ALI instrument onboard the EO-1 satellite is a technology demonstration that serves as a prototype for the Landsat Data Continuity Mission. The ALI observes the Earth in 10 spectral bands whose spectral region ranges from 0.43 to $2.35 \mu \mathrm{m}$, and the pan band has a spatial resolution of $10 \mathrm{~m}$, with the spectral region ranging from 0.48 to $0.69 \mu \mathrm{m}$. The ALI dataset is calibrated from digital number to radiance value. With the help of the $6 \mathrm{~S}$ radiometric transfer model and a climate dataset, the atmospheric effects were removed to build the reflectance imagery [41,42].

\subsection{Sentinel-2 Dataset}

Sentinel-2A was launched on 23 June 2015 as a polar-orbiting, multispectral high-resolution imaging mission for land monitoring [43]. In this paper, a cloud-free multispectral high-resolution image from the Sentinel-2 satellite was acquired on 30 May 2016, consisting of 13 spectral channels in the visible, near infrared, and short wave infrared part of the spectrum. Among these 13 bands, 3 channels are designed to detect the coastal aerosol $(0.443 \mu \mathrm{m})$, the water vapour $(0.945 \mu \mathrm{m})$, and the cirrus $(1.375 \mu \mathrm{m})$, in which the spatial resolution is $60 \mathrm{~m}$. The spatial resolution of the visible bands $2-4$ and NIR band 8 (whose spectral region ranges from 0.705 to) is $10 \mathrm{~m}$, and the spatial resolution of bands 5-7 (ranging from 0.705 to $0.783 \mu \mathrm{m}$ ), band $8(0.865 \mu \mathrm{m}$ ), and bands 11 and 12 (whose wavelengths are $1.610 \mu \mathrm{m}$ and $2.190 \mu \mathrm{m}$, respectively) is $20 \mathrm{~m}$. The satellite dataset used in this study is a Level $1 \mathrm{C}$ product. Before classification, the Level $1 \mathrm{C}$ multi-spectral images were processed into Level 2A 
reflectance images. This step was accomplished using the Sentinel 2 Level 2A Processor (Sen2Cor) plugged into the Sentinel Application Platform (SNAP) software provided by the European Space Agency (ESA) official website [44] with the anniversary dataset, water vapor and cloud detecting bands (for more details, please refer to the official website [45]).

\subsection{Landsat Dataset}

Landsat 2 multispectral scanner (MSS), Landsat 5 thematic mapper (TM) and enhanced thematic mapper (ETM+), and Landsat 8 operational land imager (OLI) images were selected to conduct a spatiotemporal analysis of the Beidagang wetland. The spatial resolution of the MSS sensor on board Landsat 2 is approximately $79 \mathrm{~m}$ and is often processed to the pixel size of $60 \mathrm{~m}$ [46]. The TM sensors on board the Landsat $4 / 5$ satellites have a spatial resolution of $30 \mathrm{~m}, 6$ spectral channels ranging from $0.4 \mu \mathrm{m}$ to $2.25 \mu \mathrm{m}$, a sixth band, and a thermal-spectral channel $(10.45 \sim 12.42 \mu \mathrm{m})$ with a spatial resolution of $120 \mathrm{~m}$. The Landsat ETM+ sensor has spatial resolutions of $30 \mathrm{~m}$ for the six reflective bands, $60 \mathrm{~m}$ for the thermal band, and $15 \mathrm{~m}$ for the panchromatic band. Compared with Landsat ETM+ images, Landsat 8 OLI images consist of nine spectral bands in the VNIR and SWIR spectral regions. Bands 1 to 7 and 9 have a spatial resolution of $30 \mathrm{~m}$. The resolution of band 8 (panchromatic) is $15 \mathrm{~m}$, and bands 10 and 11 are thermal-spectral channels with a spatial resolution of $100 \mathrm{~m}$, which are used to provide accurate surface temperatures.

In this study, long-term series of cloud-free summer Landsat satellite data from 1975 to 2015 were collected at intervals of 5 years and used to evaluate the dynamics of the wetland and vegetation fractions in the Beidagang wetland. Landsat 8 OLI dataset of 2016 was also collected and used for classification testing with the combination of the abovementioned ALI and Sentinel-2 dataset. All the Landsat satellite datasets were freely obtained from USGS website [47] and are reflectance images that were corrected by removing atmospheric effects (See Table 1). The preprocessing of the Landsat $4-5$ and 7 images used the radiative transfer model $6 \mathrm{~S}$, while the pressure, water, and air temperature measurements were obtained from the National Centres for Environmental Prediction (NCEP) grid dataset. The preprocessing of the Landsat 8 images used the radiative transfer model internal algorithm, the water vapor and air temperature measurements were obtained from Moderate Resolution Imaging Spectroradiometer (MODIS) Climate Modelling Grid-Aerosol (CMA), and the pressure was calculated internally based on the elevation. For detailed information we refer readers to $[48-50]$.

Table 1. Summary of long-term series of Landsat satellite dataset used in this study. Percent cloud cover corresponds with the date/time of remotely sensed data collection.

\begin{tabular}{cccc}
\hline Year & Landsat Date & Sensor & Cloud Cover (\%) \\
\hline 1976 & $09 / 19$ & Landsat 2/MSS & 0.00 \\
1980 & $09 / 17$ & Landsat 2/MSS & 0.00 \\
1985 & $08 / 28$ & Landsat 5/TM & 5.93 \\
1990 & $09 / 11$ & Landsat 5/TM & 1.46 \\
1995 & $08 / 24$ & Landsat 5/TM & 1.15 \\
2000 & $08 / 21$ & Landsat 5/TM & 6.39 \\
2005 & $09 / 04$ & Landsat 5/TM & 7.50 \\
2010 & $10 / 04$ & Landsat 5/TM & 0.16 \\
2015 & $10 / 02$ & Landsat 8/OLI & 0.33 \\
2016 & $05 / 29$ & Landsat 8/OLI & 7.43 \\
\hline
\end{tabular}

\subsection{Field Survey Dataset}

In this study, the field survey was carried out on 27 June 2016. Numerous photographs were collected using a digital camera (a Cannon EOS 60D, whose resolution is 18.1 megapixels and uses an APS-C CMOS Sensor, produced by the Cannon Company, made in Japan) (see Figure 2, these photos correspond to the location in the red circle shown in Figure 1c). Additionally, ground truth data was 
collected through a global positioning system (GPS) terminal at approximately 238 points within the study area (approximately 82 polygons were delineated) and another 105 points around the study area to validity the classification results from the ALI dataset (approximately 37 polygons were delineated). Due to the difficulty of accessing the marsh areas, most of the polygons were collected on both sides of roads. These field survey datasets were used to validate the accuracy of the improved IT2FCM* algorithm.

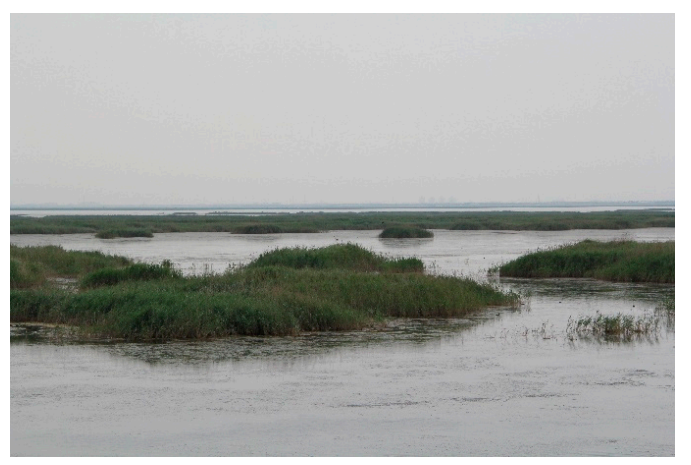

(a)

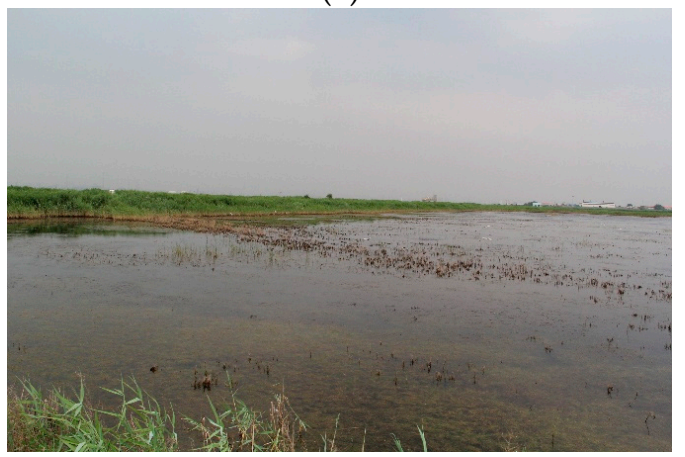

(c)

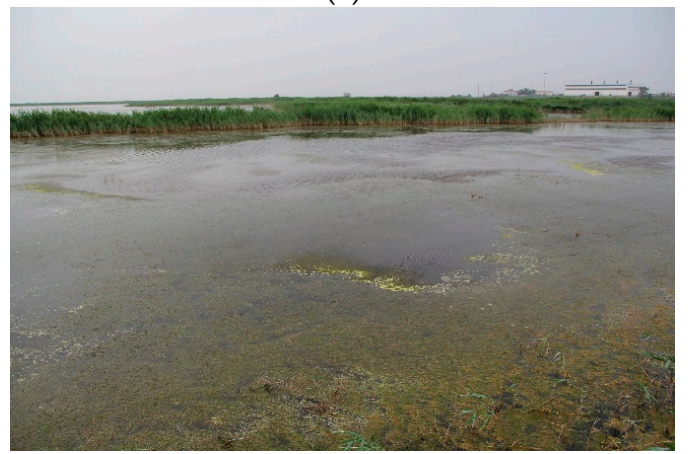

(e)

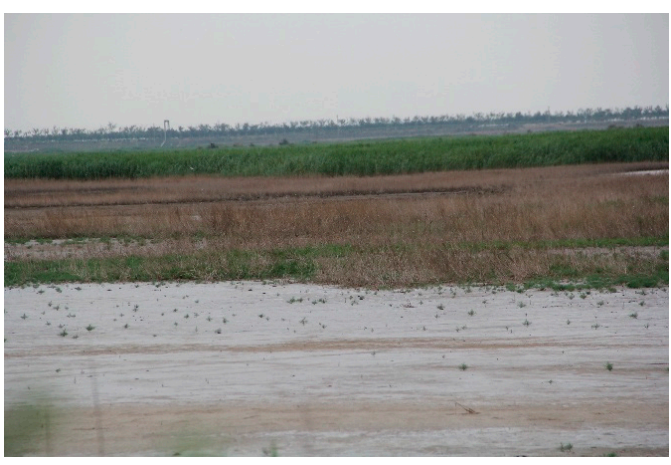

(b)

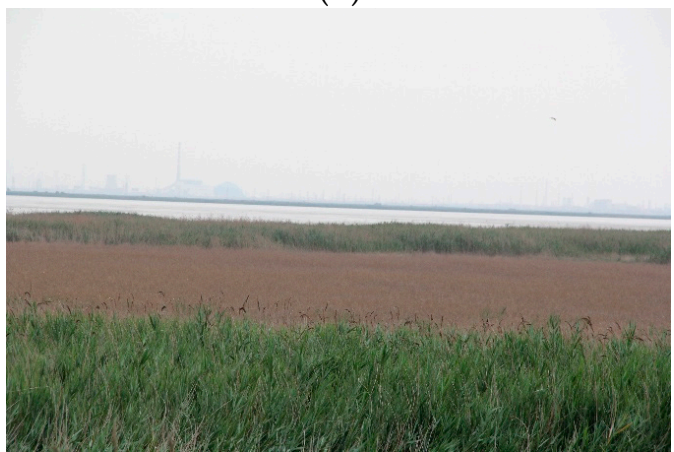

(d)

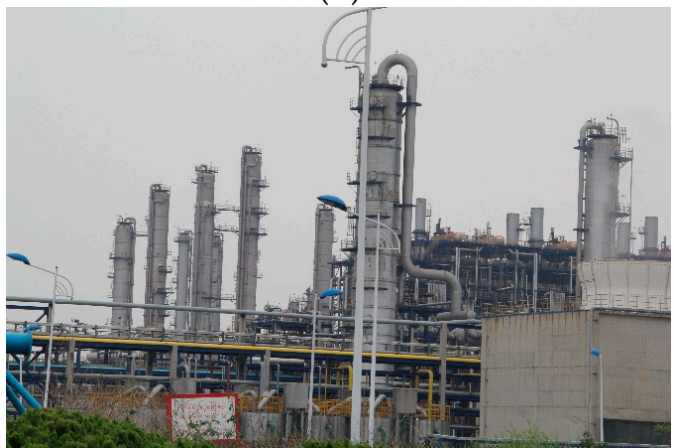

(f)

Figure 2. (a-f) The field observations on 27 June 2016; a through e correspond to some photos of different vegetation types and $\mathrm{f}$ is the oil finery which corresponds to region $\mathrm{C}$ (in the red circle) in Figure 1c.

The entire flowchart of the study is given in Figure 3. 


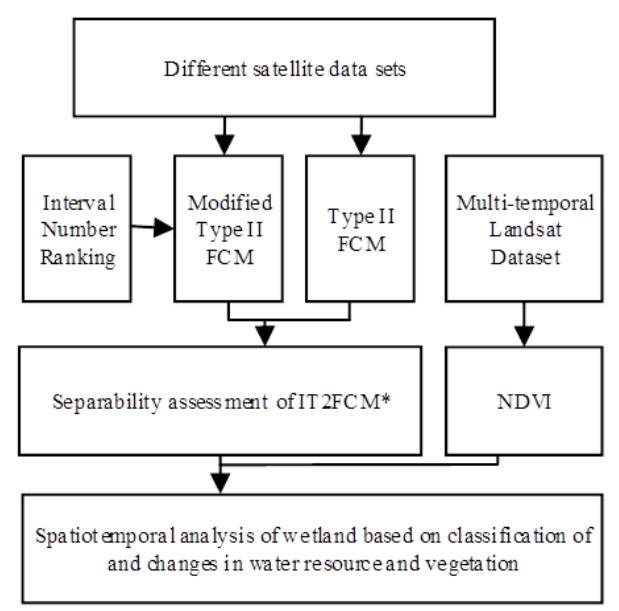

Figure 3. Flowchart of the spatiotemporal analysis of the wetland based on long-term series of Landsat satellite data.

\section{Methodology}

\subsection{Introduction of IT2FCM}

The class number $C$ and the fuzzifier $m$ are two parameters that can be set by users [51] in FCM. The cluster centres are expressed by real number vectors, and the distance between a sample and the cluster centres is used to determine the membership grade of a sample belonging to one class. The fuzzy membership grades of a sample of a specific class can differ for different values of the fuzzifier $\mathrm{m}$ for a given classification number, $\mathrm{C}$ [23,52]. As mentioned above, Classical FCM clustering methods cannot handle uncertainty of membership degree. The concept of a type-2 fuzzy set was introduced by [31] as an extension of the concept of an ordinary fuzzy set (henceforth called a type-1 fuzzy set). A type-1 fuzzy set has a crisp membership degree, whereas a type-2 fuzzy set has fuzzy membership degrees-it can be considered as a "fuzzy-fuzzy set". Such sets are particularly useful in circumstances when it is difficult to determine an exact membership function for a fuzzy set; hence, type-2 fuzzy sets are useful for incorporating uncertainties. Hwang and Rhee proposed IT2FCM based on the interval type II fuzzy set (IT2FS) to address uncertainty in the choice of $\mathrm{m}$, which uses lower and upper membership grades or functions to address the uncertainty in the fuzzy membership value [52]. The lower and upper membership functions are constructed using two fuzzifiers, $m_{1}$ and $m_{2}$, in IT2FCM. Then, two objective functions can be expressed as follows:

$$
\left\{\begin{aligned}
J_{m 1}(U, v) & =\sum_{k=1}^{N} \sum_{i=1}^{C}\left(u_{i k}\right)^{m 1} d_{i k}^{2} \\
J_{m 2}(U, v) & =\sum_{k=1}^{N} \sum_{i=1}^{C}\left(u_{i k}\right)^{m 2} d_{i k}^{2}
\end{aligned}\right.
$$

where $d_{i k}=\left\|x_{k}-v_{i}\right\|$ is the distance metric between the sample $x_{k}$ and the cluster centroid $v_{i}, C$ is the number of clusters, $\mathrm{N}$ is the number of samples, $\mathrm{U}$ is the matrix of membership values, $k$ is the sample, $i$ is the clusters, and $u_{i k}$ and $\overline{u_{i k}}$ are the lower and upper membership grades, respectively, which can be expressed as follows:

$$
\begin{gathered}
\overline{u_{i k}}=\left\{\begin{array}{l}
\frac{1}{\sum_{j=1}^{C}\left(d_{i k} / d_{j k}\right)^{2 /(m 1-1)}} \text { if } \frac{1}{\sum_{j=1}^{C}\left(d_{i k} / d_{j k}\right)}<\frac{1}{C} \\
\frac{1}{\sum_{j=1}^{C}\left(d_{i k} / d_{j k}\right)^{2 /(m 2-1)}} \text { if } \frac{1}{\sum_{j=1}^{C}\left(d_{i k} / d_{j k}\right)} \geq \frac{1}{C}
\end{array}\right. \\
\underline{u_{i k}}=\left\{\begin{array}{l}
\frac{1}{\sum_{j=1}^{C}\left(d_{i k} / d_{j k}\right)^{2 /(m 1-1)}} \text { if } \frac{1}{\sum_{j=1}^{C}\left(d_{i k} / d_{j k}\right)} \geq \frac{1}{C} \\
\frac{1}{\sum_{j=1}^{C}\left(d_{i k} / d_{j k}\right)^{2 /(m 2-1)}} \text { if } \frac{1}{\sum_{j=1}^{C}\left(d_{i k} / d_{j k}\right)}<\frac{1}{C}
\end{array}\right.
\end{gathered}
$$


where $i=1,2, \ldots, \mathrm{C}$ and $k=1,2, \ldots, \mathrm{N}$.

The cluster centroid $v_{i}$ is represented by the interval between $\mathrm{v}^{\mathrm{L}}$ and $\mathrm{v}^{\mathrm{R}}$ and computed in the same way as in FCM methods: $v_{i}=\sum_{k=1}^{N}\left(u_{i k}\right)^{m} x_{k} / \sum_{k=1}^{N}\left(u_{i k}\right)^{m}$. The KM algorithm [53] is adopted to determine $\mathrm{v}^{\mathrm{L}}$ and $\mathrm{v}^{\mathrm{R}}$, and $v_{i}$ can be obtained via type reduction: $v_{i}=\left(v_{i}^{L}+v_{i}^{R}\right) / 2$. The membership grades can be determined as follows:

$$
u_{i j}=\left(u_{i j}^{L}+u_{i j}^{R}\right) / 2, i=1,2, \ldots, \mathrm{C} ; j=1,2, \ldots, \mathrm{N}
$$

In addition, $u_{i j}^{L}$ and $u_{i j}^{R}$ can be determined as follows:

$$
\begin{aligned}
& u_{i j}^{L}=\sum_{l=1}^{m} u_{i j}^{l} / \text { m where } u_{i j}^{l}=\left\{\begin{array}{c}
\overline{u_{i j}} \text { if } x_{i l} \text { uses } \overline{u_{i j}} \text { for } v^{L} \\
\underline{u_{i j}} \text { otherwise }
\end{array}\right. \\
& u_{i j}^{R}=\sum_{l=1}^{m} u_{i j}^{l} / \text { m where } u_{i j}^{l}=\left\{\begin{array}{c}
\overline{u_{i j}} \text { if } x_{i l} \text { uses } \overline{u_{i j}} \text { for } v^{R} \\
\underline{u_{i j}} \text { otherwise }
\end{array}\right.
\end{aligned}
$$

where $M$ is the number of sample features. Then, the class to which a sample belongs can be determined by the following rule: if $u_{i k}>u_{j k}$ for $j=1,2, \ldots, C$ and $i \neq j$, then $x k$ is assigned to cluster $i$.

Cluster centres are expressed as real vectors in existing FCMs, so errors of these centres cannot be dealt with effectively. The interval centroids of all clusters must be type reduced to singleton values. Moreover, the type 2 fuzzy membership functions are defuzzified into type 1 fuzzy membership functions during each iteration; therefore, some information is lost [54]. All the derivative methods of IT2FCM have the same deficiency, including the interval type 2 fuzzy possibilistic c-means (IFPCM) [55], interval-valued possibilistic FCM (IPFCM) [56], general type 2 FCM (GT2 FCM) [57], interval type 2 FCM clustering with spatial information (IIT2-FCM) [24], and the kernel interval-valued FCM (KIFCM) [30] clustering algorithms.

The spectral characteristic curves of almost all geographical features should be bands with a certain range (i.e., not curves) [58,59]; therefore, the same spectrum in a satellite image may correspond to a different classification in the natural or real world [60]. The sensors, data-acquisition process, processing steps, and conversion and transmission processes may produce uncertainty in remote sensing data [59,61-63].

\subsection{IT2FCM* Algorithm}

The lower and upper membership functions are constructed using the two fuzzifiers: $m_{1}$ and $m_{2}$, but IT2FCM and its extended algorithm such as IIT2-FCM still have some faults which are discussed in the preceding section. Therefore, we proposed the IT2FCM ${ }^{*}$ based on based on the interval number distance and ranking. There are some distance definitions between interval numbers. For example, the Euclidean distance between interval numbers is commonly used, but its obvious default is that this definition considers only the endpoints of the interval numbers. We tested these distance definitions in IT2FCM ${ }^{*}$ and proved that the definition proposed by Li et al. which is an extension of the definition proposed by Bertoluzza et al. is more effective than others [64]. Hence, the interval number distance proposed in [64] was adopted in the improved IT2FCM ${ }^{*}$ algorithm. Let $\bar{a}=\left[a^{-}, a^{+}\right]$and $\bar{b}=\left[b^{-}, b^{+}\right]$ be two interval numbers. Then, the interval distance between $a$ and $b$ is calculated as follows:

$$
\widetilde{d}(\bar{a}, \bar{b})=\left(\frac{a^{-}+a^{+}}{2}-\frac{b^{-}+b^{+}}{2}\right)+\frac{1}{3}\left[\left(\frac{a^{+}-a^{-}}{2}\right)^{2}+\left(\frac{b^{+}-b^{-}}{2}\right)^{2}\right]-\frac{1}{6}\left[(\bar{a} \cap \bar{b})^{+}-(\bar{a} \cap \bar{b})^{-}\right]^{2}
$$

Just as in IT2FCM. The lower and upper membership functions are constructed using two fuzzifiers: $m_{1}$ and $m_{2}$. Then, two objective functions can be established by Equation (1). 
All the cluster centroids are interval number vectors in IT2FCM* Thus, the interval vector distance between a sample and an interval cluster centroid can be expressed as follows:

$$
\widetilde{d}(x, \widetilde{v})=\left(\sum_{i=0}^{M} d^{2}\left(x_{i}, \widetilde{v}_{i}\right)\right)^{\frac{1}{2}}=\left(\sum_{i=0}^{M}\left(x_{i}-\frac{\widetilde{v}_{i}^{-}+\widetilde{v}_{i}^{+}}{2}+\frac{1}{3}\left(\frac{\widetilde{v}_{i}^{+}+\widetilde{v}_{i}^{-}}{2}\right)^{2}\right)^{2}\right)^{\frac{1}{2}}
$$

where $x$ is a sample, $\widetilde{v}$ is an interval number vector, $i=1,2, \ldots, M$, and $M$ is the number of features. Each $\widetilde{v}_{i}$ in $\widetilde{v}$ has a lower and upper bound (e.g., $\widetilde{v}_{i}^{-}$and $\widetilde{v}_{i}^{+}$). Based on the interval number distance method and the two different fuzziness parameters, $\mathrm{m}_{1}$ and $\mathrm{m}_{2}$, the lower and upper membership grades of each sample can be expressed as follows:

$$
\begin{gathered}
\overline{u_{i k}}=\left\{\begin{array}{l}
\frac{1}{\sum_{j=1}^{C}\left(\widetilde{d}_{i k} / \widetilde{d}_{j k}\right)^{2 /(m 1-1)}} \text { if } \frac{1}{\sum_{j=1}^{C}\left(\widetilde{d}_{i k} / \widetilde{d}_{j k}\right)}<\frac{1}{C} \\
\frac{1}{\sum_{j=1}^{C}\left(\widetilde{d}_{i k} / \widetilde{d}_{j k}\right)^{2 /(m 2-1)}} \text { if } \frac{1}{\sum_{j=1}^{C}\left(\widetilde{d}_{i k} / \widetilde{d}_{j k}\right)} \geq \frac{1}{C}
\end{array}\right. \\
\underline{u_{i k}}=\left\{\begin{array}{l}
\frac{1}{\sum_{j=1}^{C}\left(\widetilde{d}_{i k} / \widetilde{d}_{j k}\right)^{2 /(m 1-1)}} \text { if } \frac{1}{\sum_{j=1}^{C}\left(\widetilde{d}_{i k} / \widetilde{d}_{j k}\right)} \geq \frac{1}{C} \\
\frac{1}{\sum_{j=1}^{C}\left(\widetilde{d}_{i k} / \widetilde{d}_{j k}\right)^{2 /(m 2-1)}} \text { if } \frac{1}{\sum_{j=1}^{C}\left(\widetilde{d}_{i k} / \widetilde{d}_{j k}\right)}<\frac{1}{C}
\end{array}\right.
\end{gathered}
$$

where $i=1,2, \ldots, C$, and $k=1,2, \ldots, N$.

The objective functions are similar to Equation (2): $v_{i}^{L}$ and $v_{i}^{R}$ are determined by the KM algorithm. Additionally, the iteration can be terminated when $J_{m}^{t+1}(U, v)-J_{m}^{t}(U, v) \leq \varepsilon$ is satisfied. The possibility ranking method between interval numbers proposed by [65] was adopted in IT2FCM*.

The lower and upper membership grades of each sample in each class are expressed by an interval number vector $\left\{\widetilde{u}_{1 k}, \widetilde{u}_{2 k}, \ldots, \widetilde{u}_{C k}\right\}=\left\{\left[\underline{u_{1 k}}, \overline{u_{1 k}}\right],\left[\underline{u_{2 k}}, \overline{u_{2 k}}\right], \ldots,\left[\underline{u_{C k}}, \overline{u_{C k}}\right]\right\}$. The probability for any two intervals in the vector can be calculated as follows:

$$
\mathrm{P}\left(\widetilde{u}_{i k} \geq \widetilde{u}_{j k}\right)=\left\{\begin{array}{c}
1 \underline{u}_{j k} \leq \bar{u}_{j k} \leq \underline{u}_{i k} \leq \bar{u}_{i k} \\
1-\frac{\left(\bar{u}_{j k}-\underline{u}_{i k}\right)^{2}}{2 L\left(\widetilde{u}_{i k}\right) L\left(\widetilde{u}_{j k}\right)} \underline{u}_{j k} \leq \underline{u}_{i k} \leq \bar{u}_{j k} \leq \bar{u}_{i k} \\
\frac{\underline{u}_{i k}+\bar{u}_{j k+}-2 \underline{u}_{j k}}{2 L\left(\tilde{u}_{i k}\right)} \underline{u}_{i k} \leq \underline{u}_{j k} \leq \bar{u}_{j k} \leq \bar{u}_{i k} \\
\frac{2 \bar{u}_{i k}-\left(\underline{u}_{j k} \bar{u}_{j k}\right)}{2 L\left(\tilde{u}_{i k}\right)} \underline{u}_{i k} \leq \underline{u}_{j k} \leq \bar{u}_{j k} \leq \bar{u}_{i k} \\
\frac{\left(\bar{u}_{j k}-\underline{u}_{i k}\right)^{2}}{2 L\left(\widetilde{u}_{i k}\right) L\left(\widetilde{u}_{j k}\right)} \underline{u}_{j k} \leq u_{i k} \leq \bar{u}_{j k} \leq \bar{u}_{i k} \\
0 \underline{u}_{j k} \leq \bar{u}_{j k} \leq \underline{u}_{i k} \leq \bar{u}_{i k}
\end{array}\right.
$$

where $L\left(\widetilde{u}_{i k}\right)=\bar{u}_{i k}-\underline{u}_{i k}$ and $L\left(\widetilde{u}_{j k}\right)=\bar{u}_{j k}-\underline{u}_{j k}$ are the widths of the interval numbers $\widetilde{u}_{i k}$ and $\widetilde{u}_{i k}$ respectively, for $i, j=1,2, \ldots, C$, and $k=1,2, \ldots, N$.

We can then obtain a possibility matrix $\mathrm{P}=\left(\mathrm{p}_{i j}, \mathrm{k}\right)$. Moreover, the ranking vector $w_{k}=\left(w_{1 k}, w_{2 k}, \ldots, w_{C k}\right)^{T}$ can be calculated by $w_{i}=\frac{1}{n(n-1)}\left(\sum_{j=1}^{n} p_{i j}+\frac{n}{2}-1\right)$, and the index of the maximum value in $\mathrm{w}_{\mathrm{k}}$ is the class index of the sample.

In general, the improved IT2FCM* algorithm includes essentially four steps. Initially, the two fuzzifiers $m_{1}$ and $m_{2}$ and the termination criterion value $\varepsilon$ are provided to initialize the lower and upper membership grade matrix $\widetilde{u}=[\underline{u}, \bar{u}]$ using a random method. Second, all the centroids $\widetilde{v}$ are computed and the membership grade matrix is updated. Here, the $v_{i}^{L}$ and $v_{i}^{R}$ relating to the centroids $\widetilde{v}$ are determined by the KM algorithm, the Euclidean distance between interval vectors is calculated using Equation (8), the lower and upper membership grade matrix $\widetilde{u}=[\underline{u}, \bar{u}]$ is calculated using Equations (9) and (10), and then the objective function is calculated via Equation (1). If $J_{m}^{t+1}(U, v)-J_{m}^{t}(U, v) \leq \varepsilon$ 
is satisfied, the algorithm moves to the next step, otherwise, it iteratively repeats the second step; Third, classify each sample using the interval number ranking method, here, the possibility matrix is calculated using Equation (11) and-based on the possibility matrix-the ranking vector $w_{k}=$ $\left(w_{1 k}, w_{2 k}, \ldots, w_{C k}\right)^{T}$ is calculated, and a sample is assigned to a cluster according to the index of the maximum value in the ranking vector. Finally, the algorithm reports the clustering results. The detailed steps in the modified IT2FCM ${ }^{*}$ algorithm are illustrated in Figure 4.

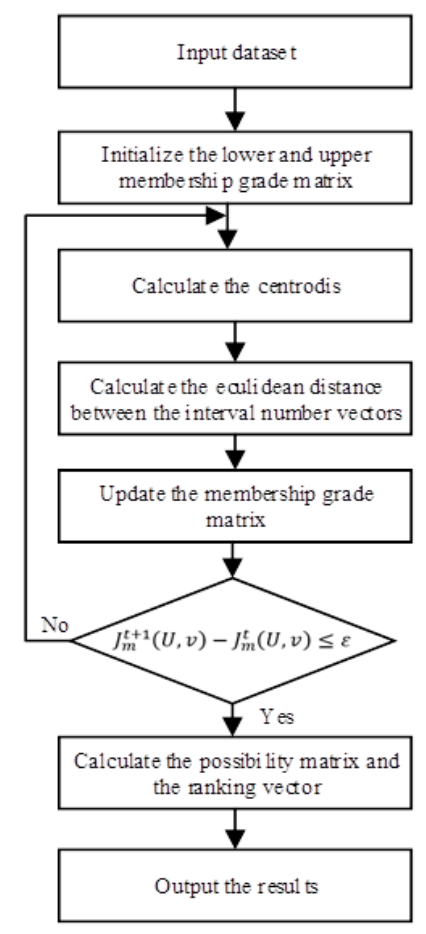

Figure 4. The flowchart of the modified IT2FCM* algorithm.

\subsection{Introduction of Four Validity Indexes}

Four cluster validity indexes are selected in this paper to validate the separability of the IT2FCM ${ }^{*}$ method. The PC- method proposed by Bezdek indicates the average relative amount of membership sharing between pairs of fuzzy subsets, in which higher values correspond to better classification results. More details can be found in [51,66]. The PE- method, also proposed by Bezdek, is a scalar measure of the amount of fuzziness in a set of results, more details can be found in [51]. The validity index FS, proposed by Fukuyama and Sugeno, is designed to measure the discrepancy between fuzzy compactness and fuzzy separation. More detailed information can be found in [67]. The validity index $\mathrm{XB}-$-, proposed by Xie and Beni, measures the average within-cluster fuzzy compactness against the minimum between-cluster separation. More detailed information can be found in $[68,69]$. Smaller values of PE-, FS- or XB- indicate better clustering performance.

\subsection{Vegetation Index}

A vegetation index can reflect the biophysical parameters of wetland vegetation, e.g., the vegetation cover and chlorophyll content, based on spectral reflectance characteristics in the red and NIR bands. This study adopted the NDVI to address the dynamics of vegetation and its impact on the wetland geomorphology. The equation for calculating the NDVI is as follows [70]:

$$
\mathrm{NDVI}=\frac{\rho_{\text {nir }}-\rho_{\text {red }}}{\rho_{\text {nir }}+\rho_{\text {red }}}
$$


where $\rho_{\text {nir }}$ is the reflectance in the NIR band, and $\rho_{\text {red }}$ is the reflectance in the red band.

\section{Experimental Results and Discussion}

In this section, the main objectives are to compare the IT2FCM approach and the modified IT2 $\mathrm{FCM}^{*}$ approach based on four validity indexes to analyse the consistency between the results of these approaches and to further evaluate the separability of the modified IT2FCM* method. In addition, the dynamics of the Beidagang wetland over the last 40 years are analysed based on a long-term series of Landsat satellite data.

\subsection{Separability Assessment Based on Four Validity Indexes for the Modified IT2FCM* Algorithm}

To evaluate the separability of classes with the modified IT2FCM* algorithm, the main goal is to measure the consistency between IT2FCM ${ }^{*}$ and the IT2FCM method. Thus, in this paper, four cluster validity indexes are adopted to assess the consistency: PC-, PE-, FS-, and XB-. As described in the previous section, the $\mathrm{PC}$ - value indicates the average relative amount of membership sharing between pairs of fuzzy subsets, thus, a higher PC- value corresponds to a better classification result, and smaller values of PE-, FS- or XB- indicate a better clustering performance. In this paper, to show the suitability and evaluate the performance of the improved IT2FCM ${ }^{*}$ algorithm, different satellite remotely sensed datasets are used, including the EO-1 ALI dataset of 22 August 2015, the Landsat 8 OLS dataset of 29 May 2016, and the Sentinel-2 satellite dataset from 30 May 2016. The associated classification results were used as examples to demonstrate the changes in the four indexes (see Table 2).

Table 2 shows that the four indexes of the IT2FCM ${ }^{*}$ method exhibit the same trends as the four indexes of the IT2FCM method. The PC- and PE- values exhibit slight changes because they account only for the membership degree (i.e., they exclude the clustering centre and source data). From Table 2, we can see that the PC- values of IT2FCM* are generally higher than those of IT2FCM. The most prominent change in these four indexes is the value of FS-, the FS- value of IT2FCM* is typically far smaller than that of IT2FCM. The values of XB- and PE- exhibit slight changes when comparing the two algorithms. According to previous results in the literature $[67,71,72]$, the larger the PC- value is and the smaller the PE-, FS- and XB- values are, the better the classification results are. The abovementioned analysis also shows that the classification results of IT2FCM* are better than those of IT2FCM. The improved IT2FCM* algorithm achieves a better performance on different multi-spectral satellite remotely sensed data.

Table 2. Comparison of validity indexes with from different satellite remote sensing data.

\begin{tabular}{cccc}
\hline Dataset & Validity Index & IT2FCM & IT2FCM* \\
\hline & PC- & 0.27 & 0.36 \\
EO-1 ALI & PE- & 1.33 & 1.28 \\
22 August 2015 & FS- & -1449.52 & -2199.84 \\
& XB- & 0.40 & 0.37 \\
& PC- & 0.22 & 0.29 \\
Landsat 8/OLS & PE- & 1.54 & 1.49 \\
29 May 2016 & FS- & $-6.041347175 \mathrm{E} 7$ & $-1.1131032418 \mathrm{E} 8$ \\
& XB- & 0.52 & 0.35 \\
Sentine-2 & PC- & 0.21 & 0.26 \\
30 May 2016 & PE- & 1.59 & 1.47 \\
& FS- & $-3.725715410 \mathrm{E} 7$ & $-7.483440017 \mathrm{E7}$ \\
& XB- & 0.30 & 0.27 \\
\hline
\end{tabular}

\subsection{Separability Assessment Based on Accuracy of the Classification Results}

In this section, the separability of classes with the IT2FCM* method was further tested based on the classification results of the different multi-spectral satellite remote sensing datasets (see Figure 5). These different satellite remotely sensed datasets are described in Section 3. For the ALI dataset, 
a different location around the study area of the Beidagang wetland was selected because the dataset lacked coverage (See Figure 5a,b). In contrast, the Landsat 8 and Sentinel-2 imagery corresponded to the study area (See Figure $5 c, d$ ). To evaluate the accuracy of the classification results, ground truth dataset was collected (See Figure $5 b, e$ ). In the study area of the Beidagang wetland, because of difficulty accessing the marshes, most of the field survey data were collected and delineated on both sides of the roads within the wetland (See Figure 5e). Then, the confusion matrix coefficients of these different satellite datasets and the accuracy of each class were evaluated based on the kappa coefficients and the overall accuracy. In the area displayed in Figure 5a, the main land cover types include water bodies, human communities and concrete roads, bare soil and small country trails, croplands and thick vegetation, and grasslands or sparse vegetation. In this study, the land cover types in this area were classified into 5 types: water, sparse vegetation, thick vegetation and cropland, bare soil and impervious surface (See Figure 5a). The overall accuracy of the results based on the ALI dataset was $89.55 \%$ with a kappa coefficient of 0.86 . In the study area of the Beidagang wetland, the land cover types were classified into 6 classes based on the Sentinel-2 and Landsat 8 datasets: water, water with submerged vegetation, emergent vegetation over water, thick emergent vegetation over wetland, vegetation on land, and human communities and bare soil (See Figure $5 c, d$ ). The overall accuracy of the results based on the Sentinel-2 dataset was $89.40 \%$ with a kappa coefficient of 0.88 , and the overall accuracy of the results based on the Landsat 8 OLS dataset was $84.55 \%$ with a kappa coefficient of 0.81 . As shown in in Figure $5 c, d$, despite the differences between the classification results due to the different spatial resolution, but the results from Sentine- 2 images maintain a good agreement with the results from Landsat 8 images. In general, the clustering results were good, which further demonstrates the separability of classes with the improved IT2FCM* algorithm.

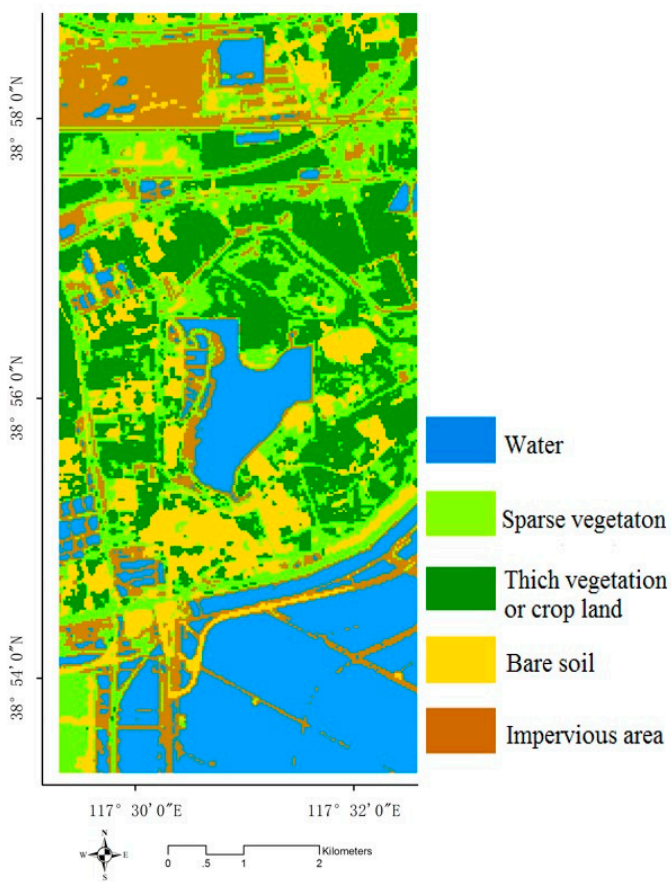

(a)

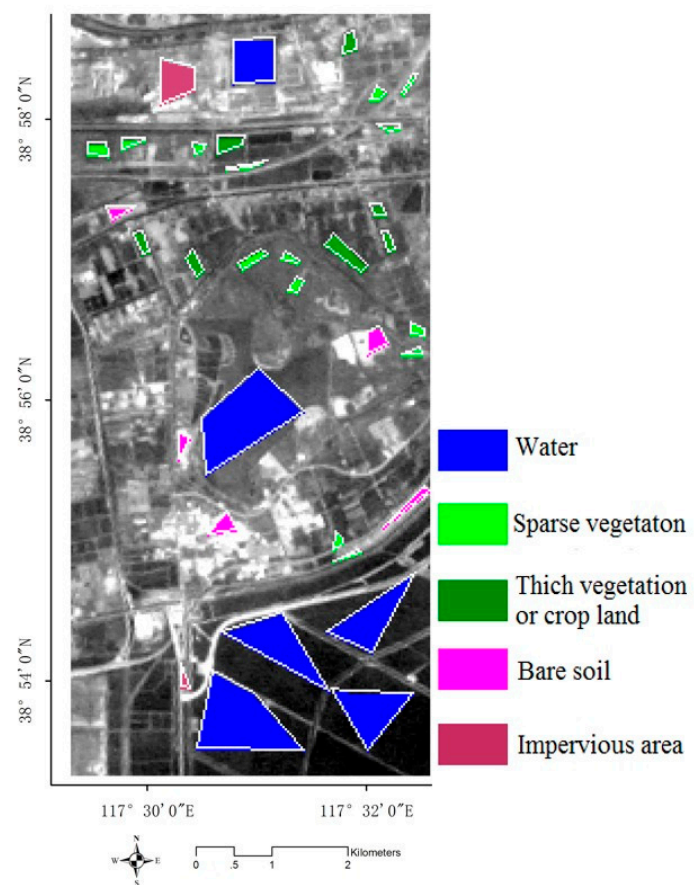

(b)

Figure 5. Cont. 


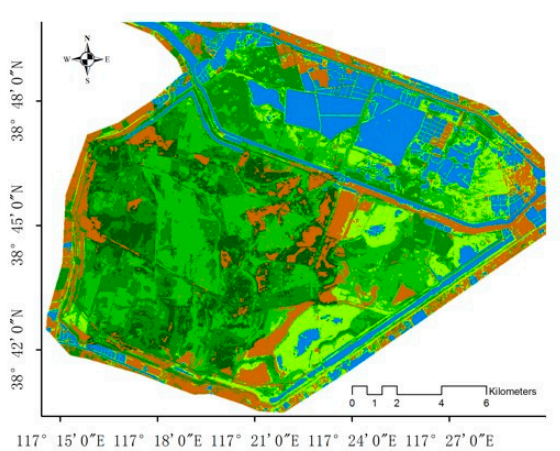

(c)

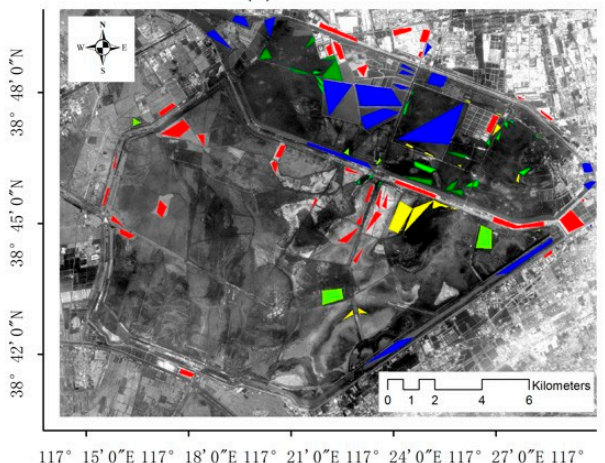

(e)

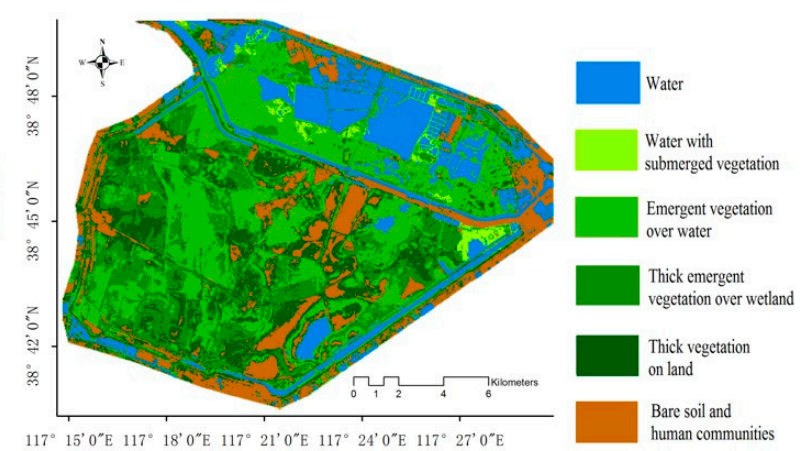

(d)

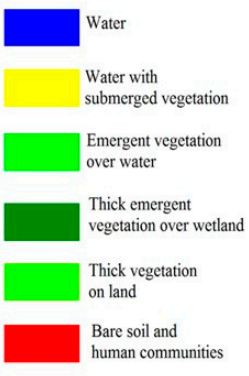

Figure 5. Classification results from different satellite multi-spectral datasets to further demonstrate the separabilty of the improved IT2FCM*: (a) the classification result from the ALI image of 22 August 2015; (b) the ground truth data collected by the field survey on 27 June 2016; (c) the classification result of the Sentinel-2 dataset acquired on 30 May 2016; (d) the classification result of the Landsat 8 remote sensing imagery acquired on 29 May 2016; and (e) the ground truth data collected by the field survey on 27 June 2016.

\subsection{Separability Assessment Based on Analysis of the Membership of Classified Land Cover Types}

In this section, the separability of the IT2FCM* algorithm was further tested based on the minimum and maximum membership values for each class by using the 2005 Landsat TM imagery as an example. Maps of the minimum and maximum membership values of the different land cover types based on the 2005 Landsat TM date set are shown in Figure 6. Notably, water and water mixed with emergent vegetation, for example, are rarely well classified, confirming the observations based on the fuzzy areas of the two classes. Even the lake does not exhibit a minimum fuzzy membership close to 0 . In fact, Figure 5 shows that the maximum membership of each land cover is close to 1 in all the maps. This result indicates that all these classes were clearly differentiated, although the ranges of membership values decreased from the maximum to the minimum maps. Thus, in general, the membership values for each class also show the good separability of the improved IT2FCM* algorithm. 

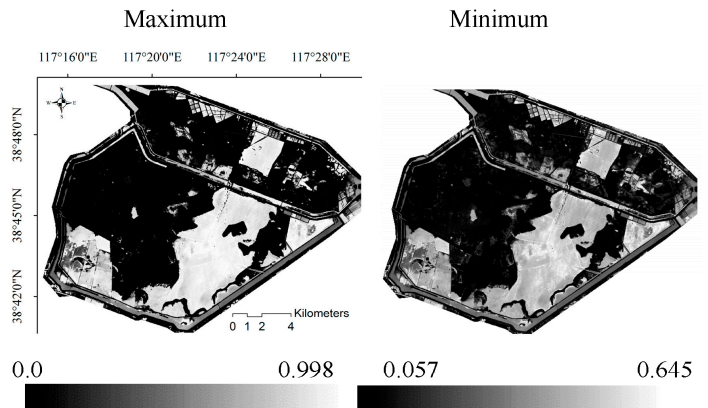

Water
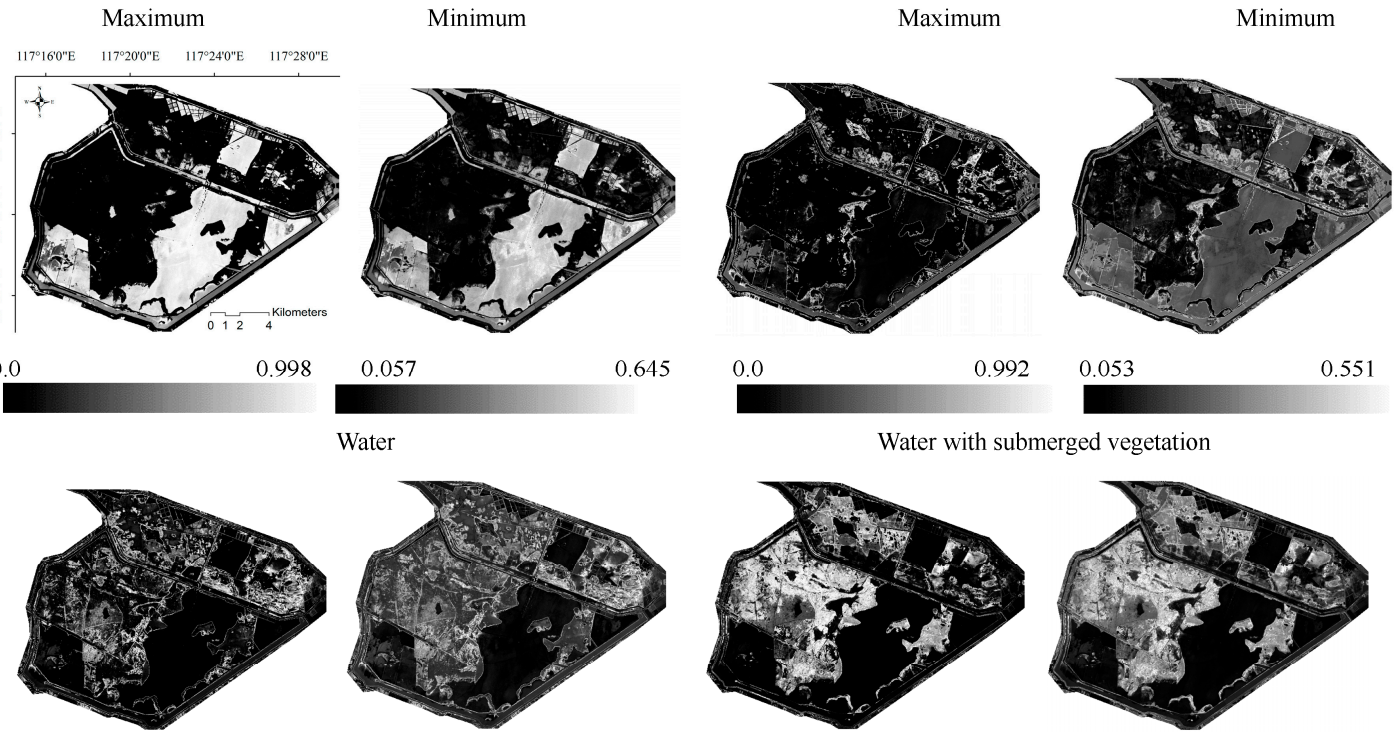

0.0

$0.992 \quad 0.073$

0.554
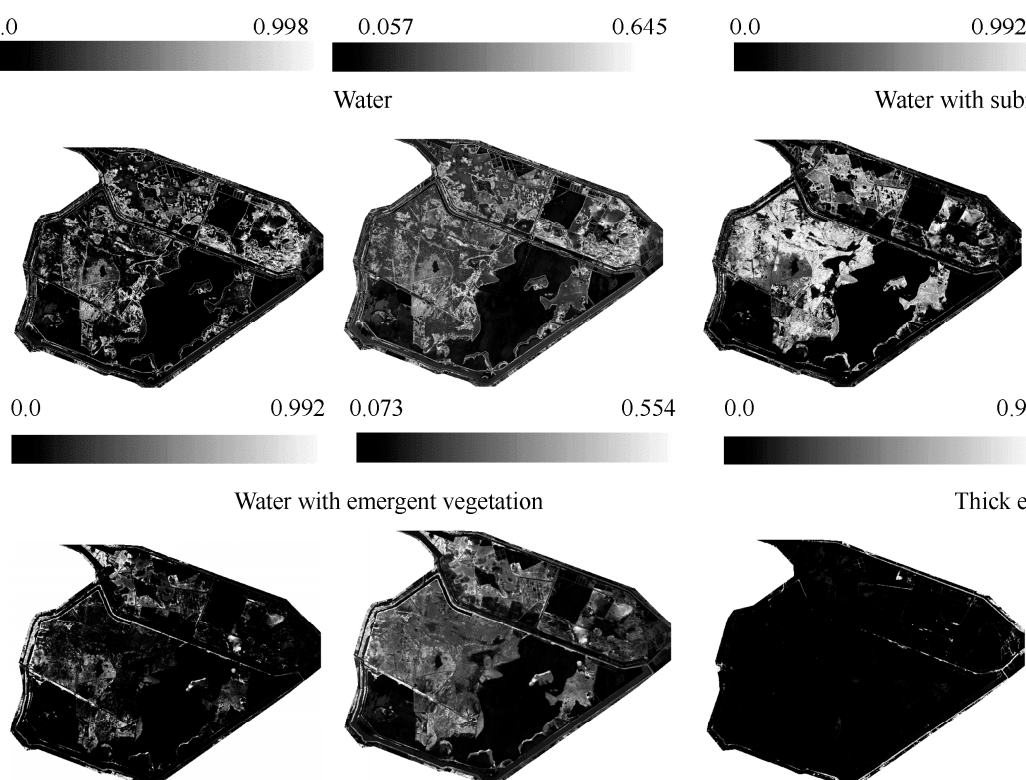

0.053

.551

Water with submerged vegetation
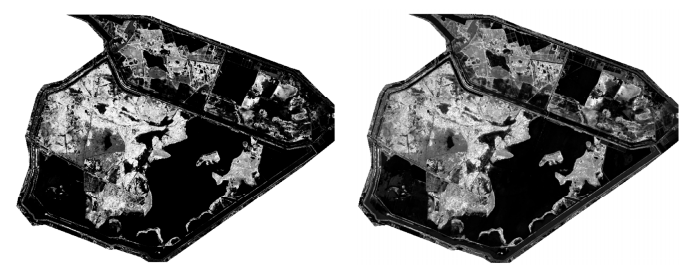

0.0

$0.994 \quad 0.062$

0.577

0.0
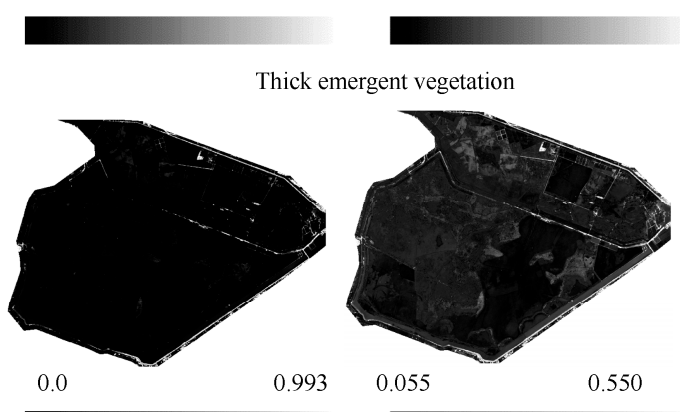

0.993

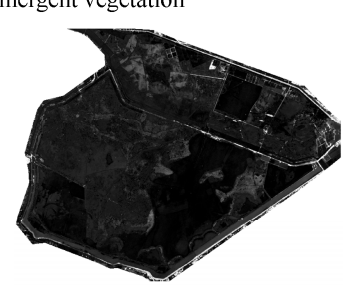

0.0

$0.991 \quad 0.057$

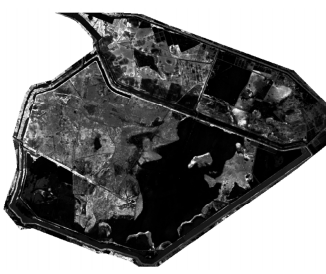

Thick vegetation on land

Bare soil and human communities

Figure 6. Maps of the type 2 fuzzy land cover types of the study area based on long-term series of Landsat satellite data starting from 4 September 2005. The land cover types in each year are divided into two columns: one is the cover type with the maximum membership, and the other is the cover type with the minimum membership.

\subsection{Forty-Year Spatial and Temporal Dynamics of the Beidagang Wetland Based on a Long-Term Series of Landsat Data}

Based on the above analysis from different aspects, the improved IT2FCM* approach shows a good separability in multi-spectral satellite remote sensing image clustering. Using the IT2FCM* method, the spatiotemporal changes of Beidagang wetland geomorphology were detected based on long-term series of multi-spectral Landsat datasets. Based on the classification results, the study area is classified into six classes: water, water with submerged or floating-leaved vegetation, water mixed with emergent vegetation, thick emergent vegetation, thick vegetation on land, and bare soil or impervious area (see Figure 7). The normalized difference vegetation index (NDVI) maps are introduced in this section to address the influence of the dynamic of NDVI on the Beidagang wetland geomorphology (See Figure 8). To address the dynamics of the Beidagang wetland and the important factors that influence these dynamics, altogether, three factors are assessed: the dynamics of water, the dynamics of the vegetation index, and the dynamics of vegetation types. The three factors are introduced to further analyse their influences on the wetland and its degradation. 


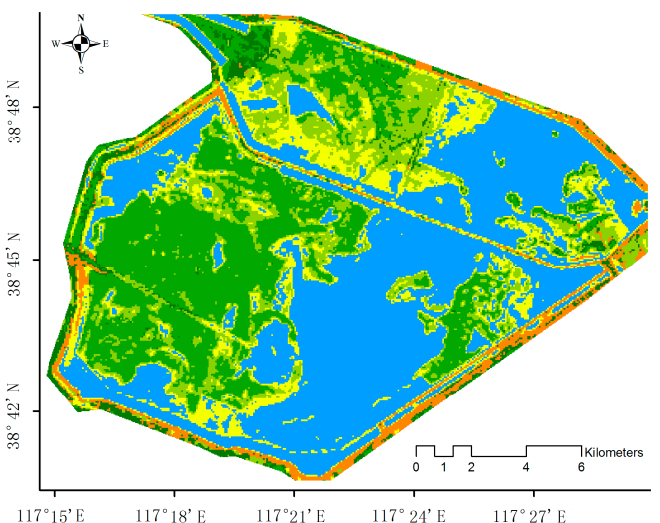

(a)

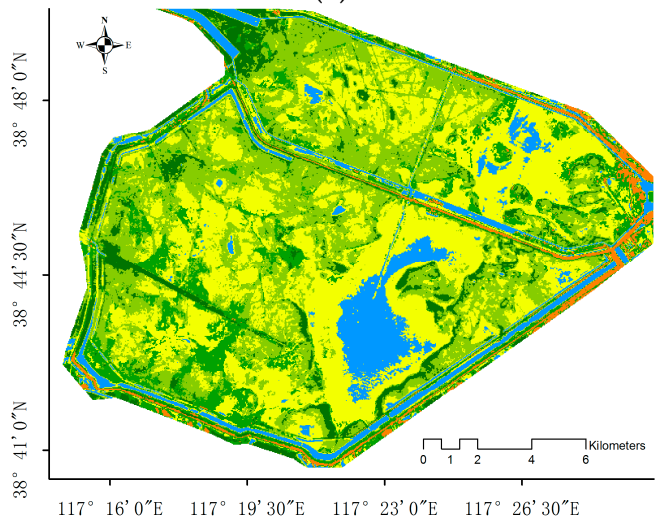

(c)

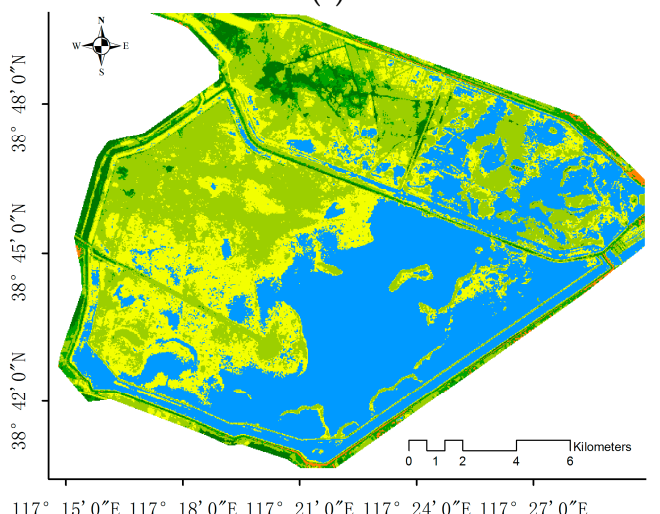

(e)

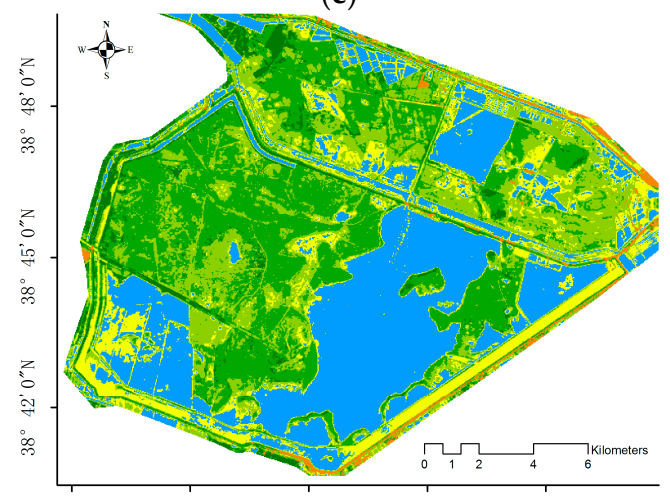

$117^{\circ} 15^{\prime} 0^{\prime \prime} \mathrm{E} 117^{\circ} 18^{\prime} 0^{\prime \prime} \mathrm{E} 117^{\circ} 21^{\prime} \mathrm{O}^{\prime \prime} \mathrm{E} 117^{\circ} 24^{\prime} 0^{\prime \prime} \mathrm{E} 117^{\circ} 27^{\prime} \mathrm{O}^{\prime \prime} \mathrm{E}$

(g)

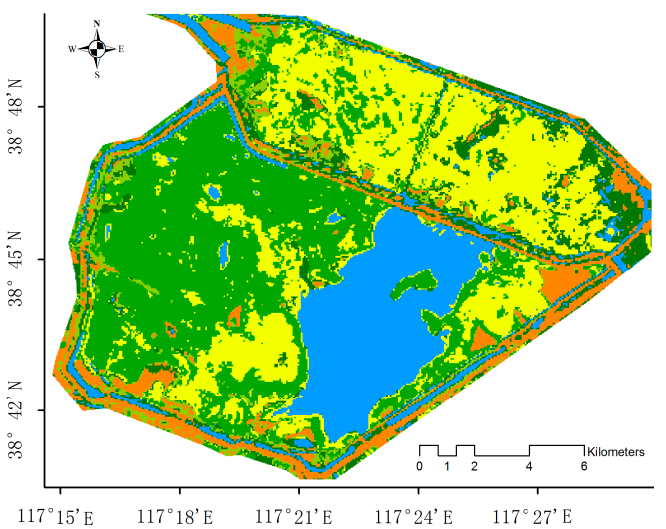

(b)

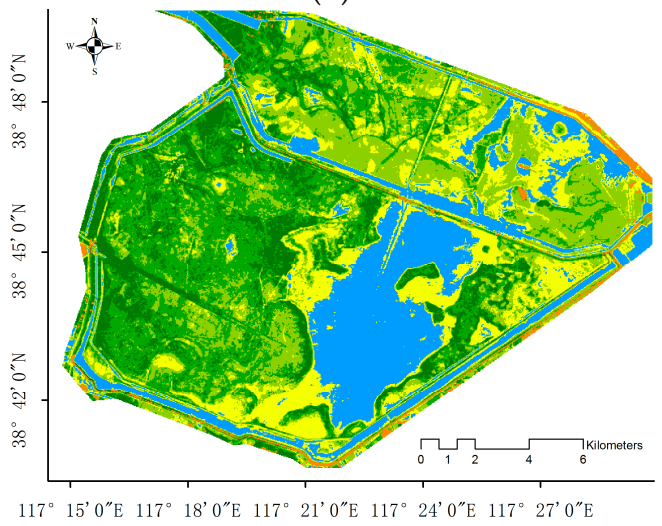

(d)

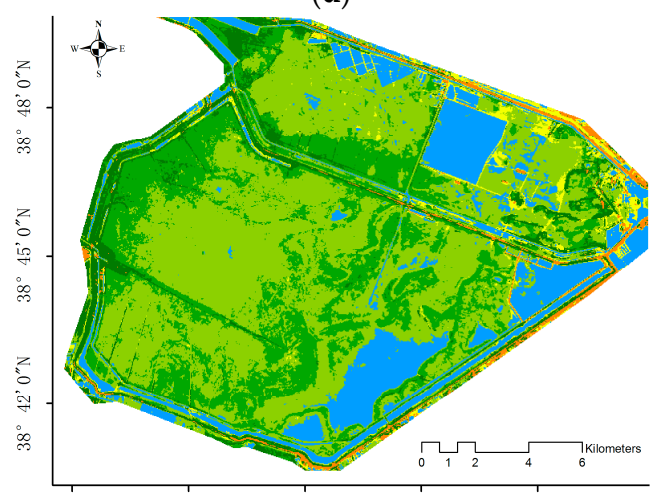

(f)

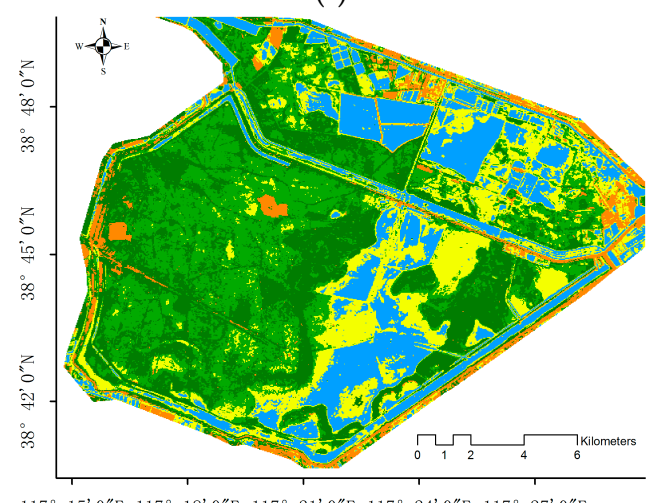

(h)

Figure 7. Cont. 


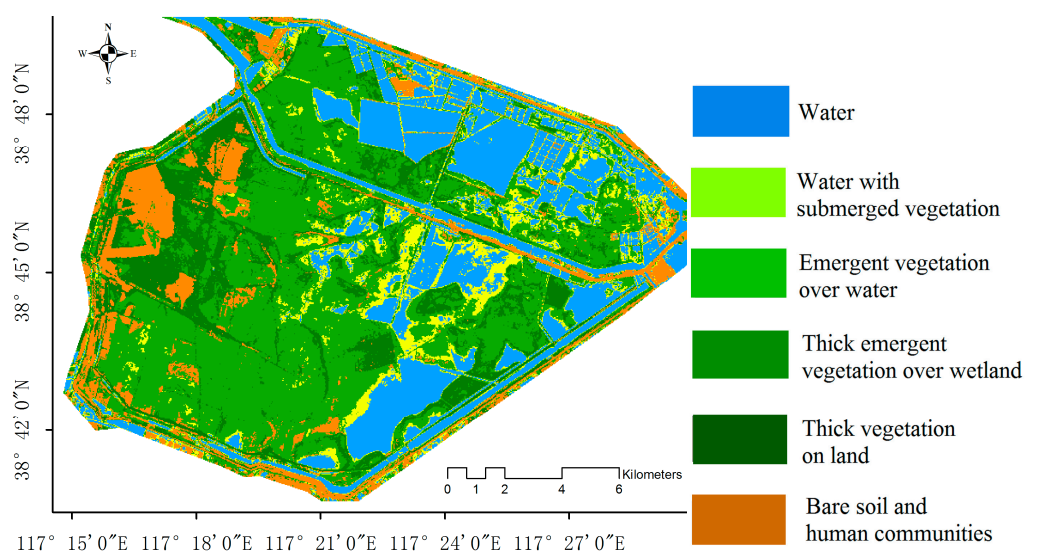

(i)

Figure 7. The classification results of the long-term series of Landsat satellite datasets from 1976 to 2015 based on the IT2FCM* algorithm. (a-i) correspond to 1976, 1980, 1985, 1990, 1995, 2000, 2005, 2010, and 2015 classification results.

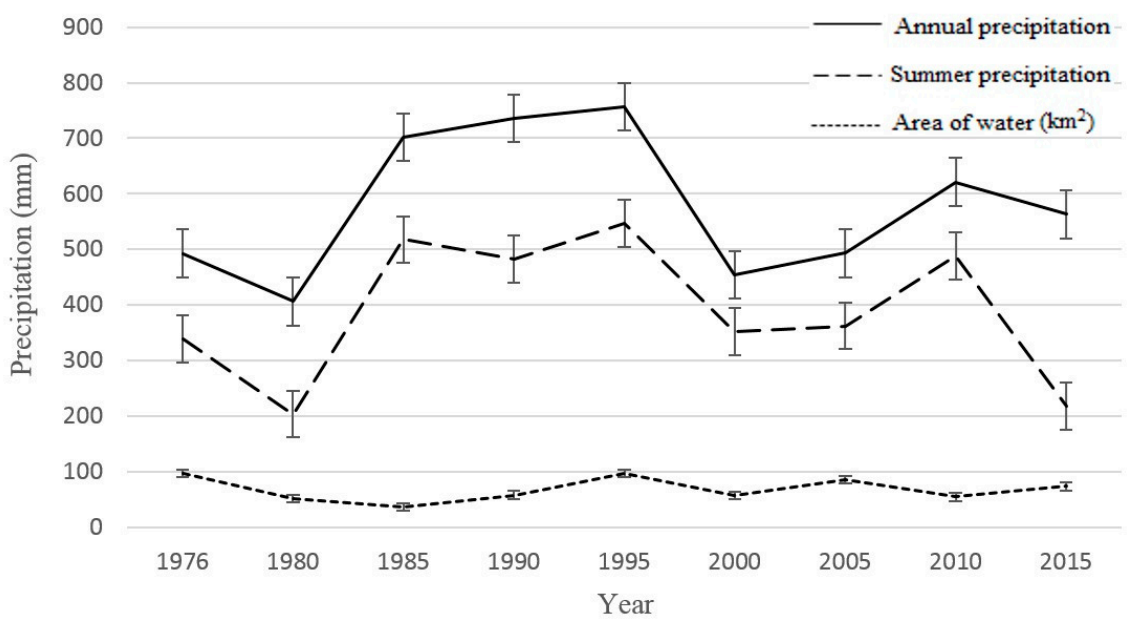

Figure 8. The relationship between the water area and precipitation (annual and summer precipitation).

\subsubsection{The Dynamics of Water and Analysis of the Associated Driving Factors}

Water is a key component of wetlands. Hence, to assess the spatial dynamics of water and address the factors that influence these dynamics, we quantitatively analysed the area of water bodies in the classification results. Additionally, precipitation data were used in the analysis (see Figures 8 and 9). Figures 7-9, show that the water area in the Beidagang wetland decreased overall from 1975 to 2015. The area of the water bodies in 1976 and 1995 were greater than in other years, especially after 1995, when the area of the water bodies obviously decreased. In 2010, and 2015, the area of water bodies occupied less than one-third of the study area. There are multiple reasons for this trend. Since 1971-and especially since 1980-the annual precipitation in the study area has averaged approximately $550 \mathrm{~mm}$, which represents a decrease of $8.9 \mathrm{~mm}$ per decade, while annual evaporation has averaged $1777 \mathrm{~mm}$. Thus, based on Figures 7-9, we can conclude that the water area trend is similar to the trends in annual precipitation and summer precipitation. In addition, the quantity of water resources has decreased since 2000; for example, the Duliujian River (see Figure 1c) had an average annual flow of 1 billion $\mathrm{m}^{3}$ into the Bohai Sea (Western Pacific) in the 1970s but only 50 million $\mathrm{m}^{3}$ in the 1990s and less than 10 million $\mathrm{m}^{3}$ since 2005 (from the Tianjin Bureau of Statistics). In addition, the increasing demands for water from agriculture and industry have influenced the 
overall quantity of water resources. For example, the Beidagang Oil factory, which is located to the southeast of Beidagang Reservoir, and other large oil refineries and chemical factories located to the northwest of the Beidagang wetland (see Figure $7 \mathrm{f}$ corresponding to Figure $1 \mathrm{c}$ ) require large quantities of water. Finally, rapid urbanization and farmland reclamation from the wetland have decreased the area of water bodies, and the construction of retaining walls has caused a decrease in intertidal zones.

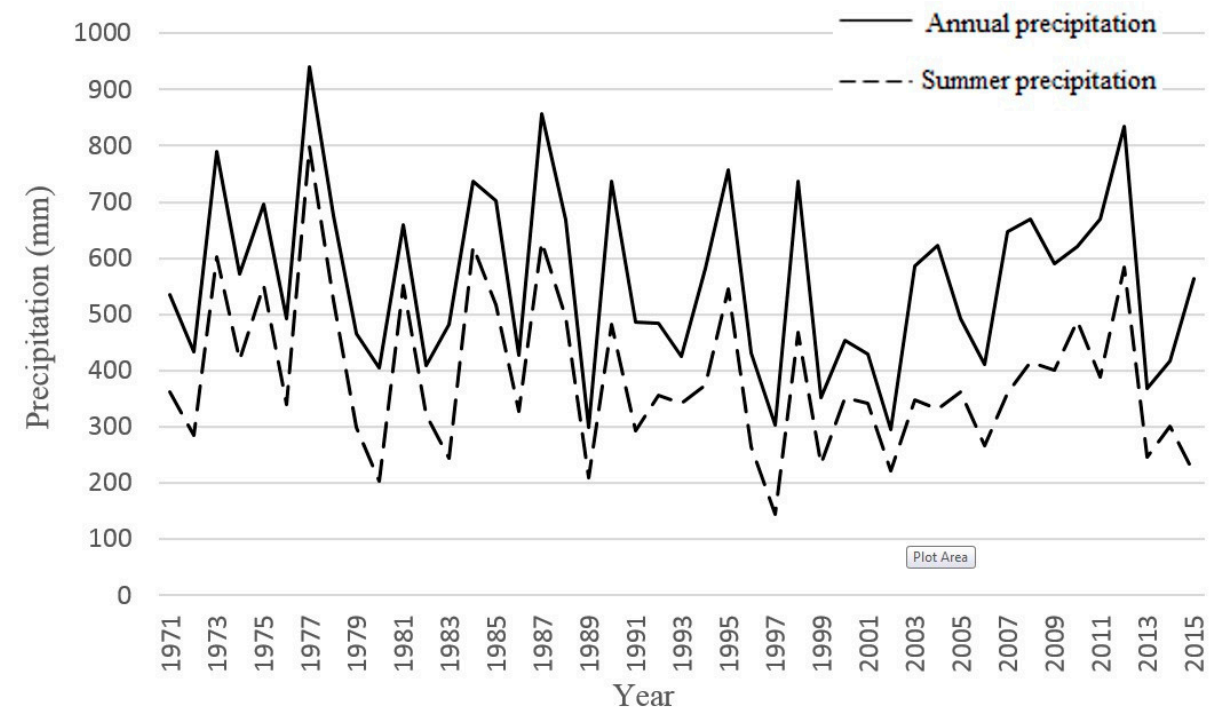

Figure 9. The annual precipitation and summer precipitation in the study area.

The spatial differences in the water area dynamics are obvious and clearly illustrated in Figures 7 and 8. The natural temporal changes in the water area of Beidagang Reservoir from 1975 to 2015 are notable: the reasons for these changes were addressed above. In addition, large spatial changes in the water area of the Beidagang wetland have occurred since 1995 (see Figure 7f-i). Figure 7f-i illustrate the areas of water in the north of the study area. These areas exhibit unnatural patterns. According to the previous literature [39] and field observations, these water bodies have been manually developed into fish farms. In addition, the conversion rate of natural waters to fishponds has increased in recent decades: before 1995, almost no fishponds existed in this region. The development of fishponds has endangered not only the local water resources, which are key wetland components but also the vegetation in the study area.

\subsubsection{The Dynamics of the Vegetation Index}

The long-term changes in the NDVI series are shown in Figure 10a-i. These figures show that there is a close relationship between vegetation coverage and the water area and depth. The value of NDVI in the wetland is relatively high compared to the value of NDVI on land except in 1995. This trend occurred because, in 1995, the water area was so large that it nearly inundated the study area. Another interesting phenomenon illustrated by these figures is that the NDVI of some water areas is greater than 0.2 because submerged plants grow in the shallow water areas. Comparing the NDVI with the classification results from 1975 to 2015, especially those in 1985, 1990 and 2000, this phenomenon is obvious. The spatial differences in NDVI are also illustrated in these figures, especially in 2015, which varies considerably in the western part of the study area (corresponding to area D delineated by a black circle in Figure 1c) due to the agricultural land development. However, the NDVI values in 1976 and 1980 differ from those in other years. Notably, many negative values can be observed in these years, especially in the bare soil and built-up area classes. However, these results may be associated with the dataset used in this study. The NDVIs in 1976 and 1980 were calculated from Landsat 2 MSS 
data, which are associated with different spectral channel settings in the NIR and red bands compared to other satellite-based datasets.

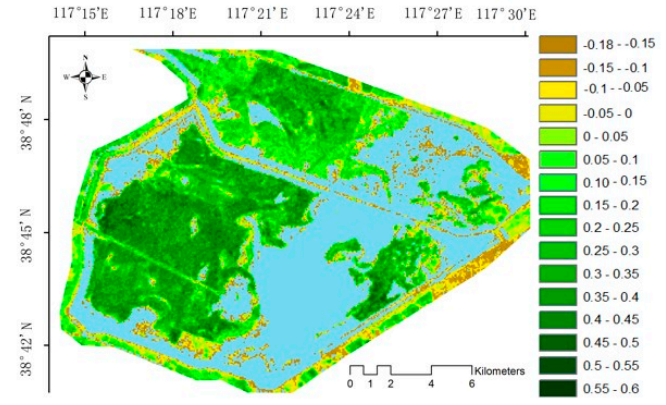

(a) 1976

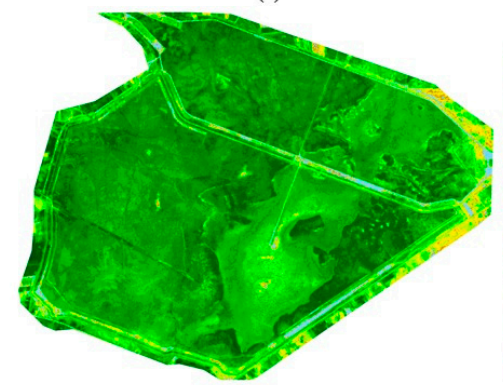

(c) 1985

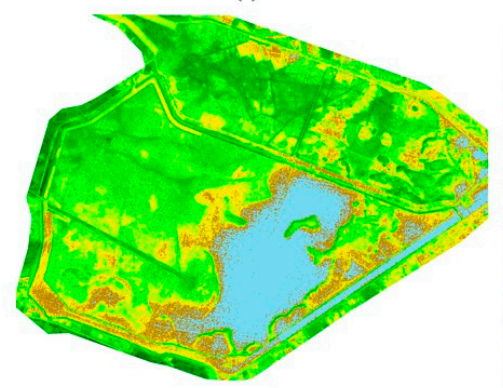

(e) 1995

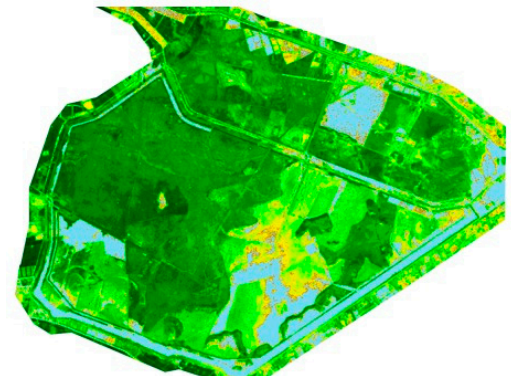

(g) 2005

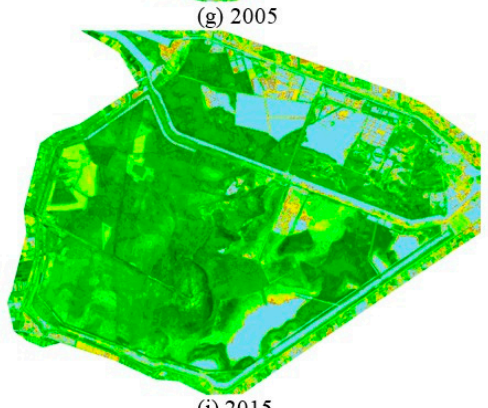

(i) 2015

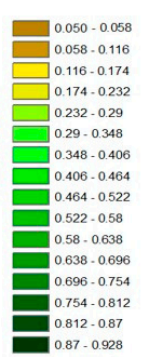

$0.87-0.928$

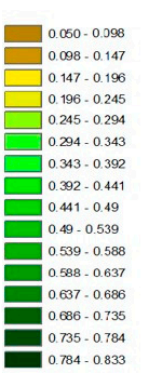

$0.735-0.784$
$0.784-0.833$

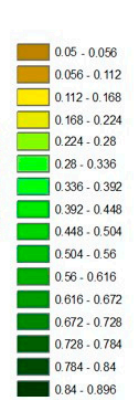

C.0.0.0.000

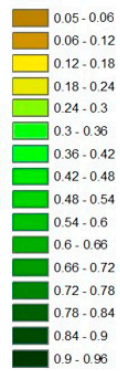

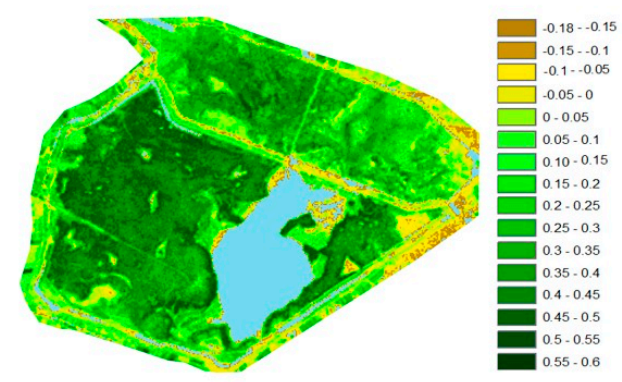

(b) 1980

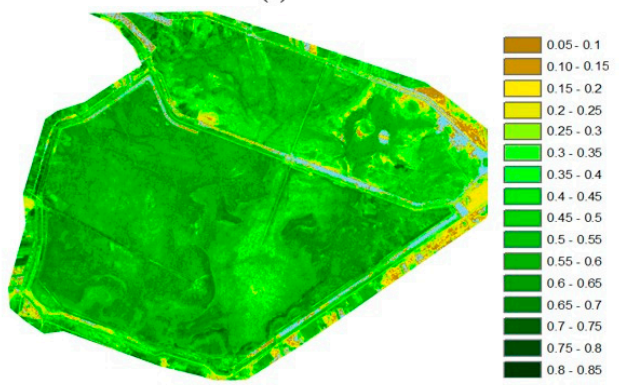

(d) 1990

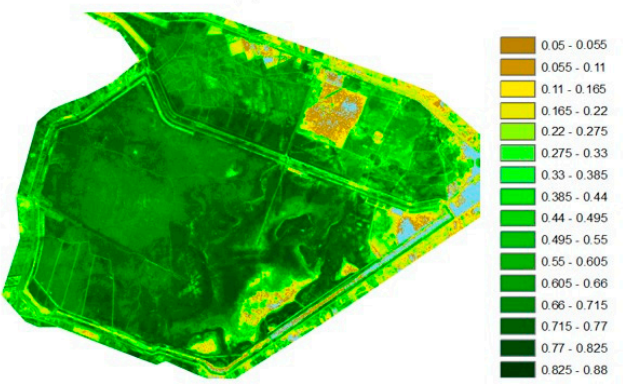

(f) 2000

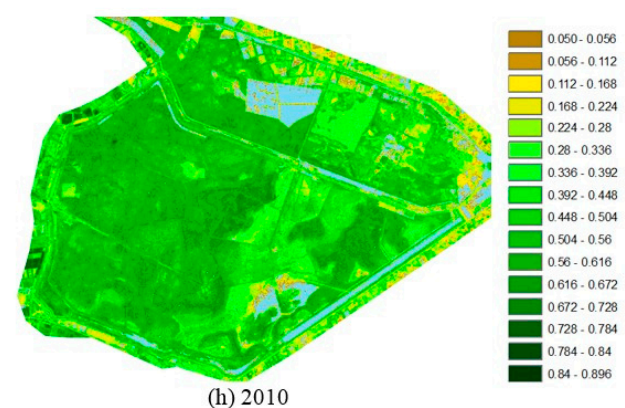

Figure 10. The NDVI of the long-term series of Landsat satellite datasets from 1976 to 2015. (a-i) correspond to 1976, 1980, 1985, 1990, 1995, 2000, 2005, 2010, and 2015 NDVI results. 


\subsubsection{Changes in Vegetation Types Based on Water Resource Dynamics}

Figure 6 shows that the quantity of natural water resources is decreasing rapidly and that the salt content is increasing, which is important for the evolution of vegetation [39]. The number of manmade pools is increasing slowly; and the area of bare land is increasing due to urban development. To assess the evolution of vegetation types in detail, a field survey and observations were performed on 27 June 2016. The geomorphology of the Beidagang wetland is mainly composed of clay, with poor soil and a high salt content. The vegetation in this region is dominated by salt-tolerant vegetation [39]. Through the field survey and observations on 27 June 2016 (see Figure 9), we found that the main vegetation is Phragmites australis (P. australis). There are patchy distributions of other vegetation types, including Suaeda salsa and Scirpus planiculmis communities. Almost no woody vegetation exists; only scattered Tamarix chinensis and Nitraria sibirica were observed. Figure 7a-i show that the vegetation is zonally distributed, which is reflective of the spatial evolution. Figure 7 shows that wet vegetation types have large NDVI values. The moderately wet vegetation mainly includes P. australis-Suaeda and Suaeda salsa. As a typical halophyte, Suaeda salsa can grow in high salt content areas, especially in the intertidal zones of salt wetlands. Additionally, it can transform saline ecological environments due to its ability to absorb the salt from the soil. Such processes can improve the soil conditions and allow other vegetation types to grow in the local environment. The xeromorphic vegetation mainly consists of P. australis-Tamarix chinensis communities, both of which are salt-tolerant plants, and some Artemisia annua-Artemisia scoparia communities (which are salt-rejecting plants) in certain land areas, especially those far from water areas. According to the field observations, the submerged vegetation class mainly includes Potamogeton pectinatus, Potamogeton crispus, Najas marina, Myriophyllum verticillatum, and some Ceratophyllum demersum communities. Aquatic vegetation grows close to or in the water and mainly includes P. australis and Scirpus planiculmis communities. Both types of vegetation, which are typical emergent vegetation communities that thrive in water environments, are water resistant and salt tolerant. The Phragmites australis-Suaeda communities are the main types of wet vegetation. They grow in and close to saline wetland and lake areas, such as in saline marshes and other areas with wet conditions and environments and.

The spatiotemporal changes in different types of vegetation suggest that the soil properties underwent significant changes, and the salt content decreased with the water content. With the vegetation types varying from aquatic vegetation to wet vegetation to xeromorphic vegetation, the salt-tolerant plants slowly shifted to salt-secreting and salt-rejecting plants. The spatiotemporal changes in vegetation types reflected not only the temporal gradient of the evolution of different vegetation but also the changes in the water content. Additionally, the salt-tolerance capability of vegetation decreased, resulting in some communities with mainly salt-rejecting vegetation, such as Artemisia annua-Artemisia scoparia. Based on the field observations, among these different types of vegetation, $P$. australis was widely distributed, implying that $P$. australis plants are adaptive to a wide range of environments. As the dominant species, $P$. australis was widely distributed in water areas with different salt contents, and the species accounted for as much as 90 percent of all plant species, forming a "sea of reeds".

\section{Conclusions}

In this study, spatiotemporal wetland cover changes were analysed using IT2FCM ${ }^{*}$, an improved approach proposed by this paper. The IT2FCM* based on interval type 2 fuzzy set was used for multi-spectral image analysis. Compared with other traditional fuzzy methods used in image clustering, the interval number ranking was adopted into this improved IT2FCM* algorithm. This addition improves its ability to address spectral uncertainty. Then, to evaluate the separability of the improved IT2FCM* algorithm, multi-spectral EO-1 ALI, Sentinel-2 and Landsat 8 OLS satellite remotely sensed datasets were used, and four validity indexes, including PC-, PE-, FS- and XB-, were introduced. The values of these four indexes of three satellite remote sensing data perform well in image clustering. To further assess the separability of the improved IT2FCM* approach, the classification 
results of the abovementioned satellite images were validated with ground truth data collected by a field survey. High overall accuracy and the kappa coefficients show that the IT2FCM* has good performance, which also demonstrated the separability of the algorithm. In addition, the maximum and minimum membership values were used to evaluate the separability of the algorithm; these results also indicate the algorithm's good separability.

Based on the above analysis of the separability of the improved IT2FCM* algorithm, the spatiotemporal changes of the Beidagang wetland geomorphology were analysed. According to spatial and temporal analyses of different land cover types in the study area, the water area has steadily decreased for many reasons including climate conditions (especially precipitation, evaporation, air and land surface temperatures, and sunshine duration), environmental factors (such as the salt content of water and the effects of erosion), and anthropogenic effects (including the construction of buildings, land use-land cover changes, and industrial and agricultural development). All these factors have influenced the studied wetland. The numbers of vegetation types, fish species, and birds, including wading birds, are decreasing. These trends will continue if the conditions do not improve in the future. For example, Phragmites and Typha angustifolia were the two dominant plant species before 2000, but the 2016 survey showed that Phragmites and Suaeda salsa have become dominant. Vegetation types underwent dramatic changes. As the volume of water resources decreased, high soil salt content has increased due to the reduction in surface runoff to the Duliujian River and more evaporation than precipitation. In turn, these changes will affect the growth of vegetation and other living creatures. The number of benthic species and the algal area have decreased notably. There were 14 benthic species in 1980, and their average density was $598 \mathrm{ind} \cdot \mathrm{m}^{-2}$ in 1980; however, in 2014, there were only 3 benthic species, and their average density was just 56 ind $\cdot \mathrm{m}^{-2}$. Moreover, migratory ocean fish have completely disappeared from the Beidagang wetland. In contrast, farmed fish now account for the majority of fish species observed. The other effects produced by these changes require further analysis.

However, we should be aware of the limitations and advantages of satellite remote sensing techniques and multispectral and moderate spatial resolution satellite data in detecting wetland land cover changes. Although satellite remote sensing cannot provide detailed information that could be obtained via a field survey, remotely sensed data can be used to continuously monitor wetlands over large areas and provide researchers with needed complementary information. To better use remote sensing techniques to monitor wetland changes, additional data should be considered. Aerial photographs or field survey data from different years should be collected to strengthen such analyses and help evaluate the results. Unfortunately, such data are rarely collected because of economic limitations and the lack of the necessary equipment.

Acknowledgments: This research is supported by grants from the China Postdoctoral Science Foundation (2016 M601181), the Tianjin Normal University Doctoral Foundation (52XB1501 and 52XB1502), the National Natural Science Foundation of China (41231170 and 41501406), the Tianjin Natural Science Foundation (17JCZDJC39700), and the National Key Basic Research Programme (2013CB733402). The authors would like to thank Mo Xunqiang (Tianjin Normal University) who provided help in identifying the vegetation types in Beidagang wetland.

Author Contributions: Hongyuan Huo wrote the manuscript and was responsible for the research design, data preparation and analysis. Jifa Guo and Hongyuan Huo conceived and designed the research and the improvement of the IT2FCM* algorithm. Zhao-Liang Li and Xiaoguang Jiang conducted the research and provided many valuable suggestions regarding the experimental design.

Conflicts of Interest: The authors declare no conflicts of interest.

\section{References}

1. Cowardin, L.M.; Carter, V.; Golet, F.C.; LaRoe, E.T. Classification of Wetlands and Deepwater Habitats of the United States; U.S. Department of the Interior Fish and Wildlife Services: Falls Church, VI, USA; 1979; Volume 79, p. 131.

2. Semlitsch, R.D.; Bodie, J.R. Are small, isolated wetlands expendable? Conserv. Biol. 1998, 12, 1129-1133. [CrossRef] 
3. Ozesmi, S.L.; Bauer, M.E. Satellite remote sensing of wetlands. Wetl. Ecol. Manag. 2002, 10, $381-402$. [CrossRef]

4. Töyrä, J.; Pietroniro, A. Towards operational monitoring of a northern wetland using geomatics-based techniques. Remote Sens. Environ. 2005, 97, 174-191. [CrossRef]

5. Kashaigili, J.J.; Mbilinyi, B.P.; Mccartney, M.; Mwanuzi, F.L. Dynamics of Usangu plains wetlands: Use of remote sensing and GIS as management decision tools. Phys. Chem. Earth Parts A/B/C 2006, 31, 967-975. [CrossRef]

6. Odum, E.P. Ecology and Our Endangered Life-Support Systems; Sinauer Associates: Washington, DC, USA, 1989.

7. Morris, J.T.; Sundareshwar, P.; Nietch, C.T.; Kjerfve, B.; Cahoon, D.R. Responses of coastal wetlands to rising sea level. Ecology 2002, 83, 2869-2877. [CrossRef]

8. Leng, P.; Song, X.; Li, Z.-L.; Ma, J.; Zhou, F.; Li, S. Bare surface soil moisture retrieval from the synergistic use of optical and thermal infrared data. Int. J. Remote Sens. 2014, 35, 988-1003. [CrossRef]

9. Gibbs, J.P. Importance of small wetlands for the persistence of local populations of wetland-associated animals. Wetlands 1993, 13, 25-31. [CrossRef]

10. Babbitt, K.J. The relative importance of wetland size and hydroperiod for amphibians in southern New Hampshire, USA. Wetlands Ecol. Manag. 2005, 13, 269-279. [CrossRef]

11. Klemas, V. Remote sensing of wetlands: case studies comparing practical techniques. J. Coast. Res. 2011, 27, 418-427. [CrossRef]

12. Robertson, L.D.; King, D.J.; Davies, C. Assessing Land Cover Change and Anthropogenic Disturbance in Wetlands Using Vegetation Fractions Derived from Landsat 5 TM Imagery (1984-2010). Wetlands 2015, 35, 1077-1091. [CrossRef]

13. Leng, P.; Song, X.; Duan, S.-B.; Li, Z.-L. A practical algorithm for estimating surface soil moisture using combined optical and thermal infrared data. Int. J. Appl. Earth Obs. Geoinf. 2016, 52, 338-348. [CrossRef]

14. Bischof, H.; Schneider, W.; Pinz, A.J. Multispectral classification of Landsat-images using neural networks. IEEE Trans. Geosci. Electron. 1992, 30, 482-490. [CrossRef]

15. Andres, L.; Salas, W.A.; Skole, D. Fourier analysis of multi-temporal AVHRR data applied to a land cover classification. Remote Sens. 1994, 15, 1115-1121. [CrossRef]

16. Muchoney, D.; Borak, J.; Chi, H.; Friedl, M.; Gopal, S.; Hodges, J.; Morrow, N.; Strahler, A. Application of the MODIS global supervised classification model to vegetation and land cover mapping of Central America. Int. J. Remote Sens. 2000, 21, 1115-1138. [CrossRef]

17. Zhu, Z.; Woodcock, C.E. Continuous change detection and classification of land cover using all available Landsat data. Remote Sens. Environ. 2014, 144, 152-171. [CrossRef]

18. Liu, J.; Zhuang, D.; Luo, D.; Xiao, X.-M. Land-cover classification of China: Integrated analysis of AVHRR imagery and geophysical data. Int. J. Remote Sens. 2003, 24, 2485-2500. [CrossRef]

19. Zhu, G.; Blumberg, D.G. Classification using ASTER data and SVM algorithms: The case study of Beer Sheva, Israel. Remote Sens. Environ. 2002, 80, 233-240. [CrossRef]

20. Harada, I.; Hara, K.; Tomita, M.; Short, K.; Park, J. Monitoring landscape changes in Japan using classification of MODIS data combined with a landscape transformation sere (LTS) model. J. Landsc. Ecol. 2015, 7, $23-38$. [CrossRef]

21. Cannon, R.L.; Dave, J.V.; Bezdek, J.C.; Trivedi, M.M. Segmentation of a thematic mapper image using the fuzzy c-means clusterng algorthm. IEEE Trans. Geosci. Electron. 1986, 24, 400-408. [CrossRef]

22. Robinson, V.; Strahler, A. Issues in designing geographic information systems under conditions of inexactness. In Proceedings of the 10th International Symposium on Machine Processing of Remotely Sensed Data: Thematic Mapper Data and Geographic Information Systems, Lafayette, IN, USA, 12-14 June 1984; pp. 198-204.

23. Fisher, P.F. Remote sensing of land cover classes as type 2 fuzzy sets. Remote Sens. Environ. 2010, 114, 309-321. [CrossRef]

24. Ngo, L.T.; Mai, D.S.; Pedrycz, W. Semi-supervising Interval Type-2 Fuzzy C-Means clustering with spatial information for multi-spectral satellite image classification and change detection. Comput. Geosci. 2015, 83, 1-16. [CrossRef]

25. Bouchachia, A.; Pedrycz, W. Enhancement of fuzzy clustering by mechanisms of partial supervision. Fuzzy Sets Syst. 2006, 157, 1733-1759. [CrossRef] 
26. Shao, P.; Shi, W.; He, P.; Hao, M.; Zhang, X. Novel approach to unsupervised change detection based on a robust semi-supervised FCM clustering algorithm. Remote Sens. 2016, 8, 264. [CrossRef]

27. Liu, H.; Zhao, F.; Jiao, L. Fuzzy spectral clustering with robust spatial information for image segmentation. Appl. Soft Comput. 2012, 12, 3636-3647. [CrossRef]

28. Zhao, F.; Fan, J.; Liu, H. Optimal-selection-based suppressed fuzzy c-means clustering algorithm with self-tuning non local spatial information for image segmentation. Expert Syst. Appl. 2014, 41, 4083-4093. [CrossRef]

29. Wang, Z.; Song, Q.; Soh, Y.C.; Sim, K. An adaptive spatial information-theoretic fuzzy clustering algorithm for image segmentation. Comput. Vis. Image Underst. 2013, 117, 1412-1420. [CrossRef]

30. Nguyen, D.D.; Ngo, L.T.; Pham, L.T.; Pedrycz, W. Towards hybrid clustering approach to data classification: Multiple kernels based interval-valued Fuzzy C-Means algorithms. Fuzzy Sets Syst. 2015, 279, 17-39. [CrossRef]

31. Zadeh, L.A. The concept of a linguistic variable and its application to approximate reasoning-I. Inf. Sci. 1975, 8, 199-249. [CrossRef]

32. Mendel, J.M.; John, R.B. Type-2 fuzzy sets made simple. IEEE Trans. Fuzzy syst. 2002, 10, 117-127. [CrossRef]

33. John, R.; Coupland, S. Type-2 fuzzy logic: A historical view. IEEE Comput. Intell. Mag. 2007, 2, 57-62. [CrossRef]

34. Stavrakoudis, D.G.; Theocharis, J.B.; Zalidis, G.C. A boosted genetic fuzzy classifier for land cover classification of remote sensing imagery. ISPRS J. Photogramm. Remote Sens. 2011, 66, 529-544. [CrossRef]

35. Ghaffarian, S. Automatic histogram-based fuzzy C-means clustering for remote sensing imagery. ISPRS J. Photogramm. Remote Sens. 2014, 97, 46-57. [CrossRef]

36. Ghosh, A.; Mishra, N.S.; Ghosh, S. Fuzzy clustering algorithms for unsupervised change detection in remote sensing images. Inf. Sci. 2011, 181, 699-715. [CrossRef]

37. Guo, J.; Huo, H.; Peng, G. Interval Type-II Fuzzy C-Means Clustering based on Interval Number Distance and Ranking. IEEE Trans. Fuzzy Syst. 2017, under review.

38. Guo, J.; Li, M.; Liu, D. Effects of urbanization on air temperature of Tianjin in recent 40 years. Ecol. Environ. Sci. 2009, 1, 29-34.

39. Chen, Q.; Liu, D.; Ma, C. Productivity and N and P Nutrition of the Phragmites australis Community in Typical Wetlands in Tianjin and Their Relationships with Environmental Factors. J. Ecol. Rural Environ. 2016, 32, 60-67.

40. National Science \& Technology Infrastructure/China Meteorological Data Service Center (CMDC). Hourly Data from Surface Meteorological Stations in China. Available online: http:/ /www.cma.gov.cn/2011qxfw/ 2011qsjgx/ (accessed on 22 August 2015).

41. Ungar, S.G.; Pearlman, J.S.; Mendenhall, J.A.; Reuter, D. Overview of the earth observing one (EO-1) mission. IEEE Trans. Geosci. Electron. 2003, 41, 1149-1159. [CrossRef]

42. Biggar, S.F.; Thome, K.J.; Wisniewski, W. Vicarious radiometric calibration of EO-1 sensors by reference to high-reflectance ground targets. IEEE Trans. Geosci. Electron. 2003, 41, 1174-1179. [CrossRef]

43. Drusch, M.; Del Bello, U.; Carlier, S.; Colin, O.; Fernandez, V.; Gascon, F.; Hoersch, B.; Isola, C.; Laberinti, P.; Martimort, P.; et al. Sentinel-2: ESA's optical high-resolution mission for GMES operational services. Remote Sens. Environ. 2012, 120, 25-36. [CrossRef]

44. Sentinel Application Platform (SNAP)/European Space Agency (ESA). Science Toolbox Exploitation Platform. Available online: http:/ /step.esa.int/main/toolboxes/snap/ (accessed on 23 June 2015).

45. Copernicus Space Component-Ground Segment team/ European Space Agency (ESA). Sentinels Data Products List. Available online: https:/ / earth.esa.int/web/sentinel/missions/sentinel-2/data-products (accessed on 23 June 2015).

46. Chander, G.; Markham, B.L.; Helder, D.L. Summary of current radiometric calibration coefficients for Landsat MSS, TM, ETM+, and EO-1 ALI sensors. Remote Sens. Environ. 2009, 113, 893-903. [CrossRef]

47. EarthExplorer/United States Geological Survey. Bulk Download of Satellite Imagery Using EarthExplorer. Available online: https:/ / earthexplorer.usgs.gov (accessed on 29 May 2016).

48. Feng, M.; Sexton, J.O.; Huang, C.; Masek, J.G.; Vermote, E.F.; Gao, F.; Narasimhan, R.; Channan, S.; Wolfe, R.E.; Townshend, J.R. Global surface reflectance products from Landsat: Assessment using coincident MODIS observations. Remote Sens. Environ. 2013, 134, 276-293. [CrossRef] 
49. Vermote, E.; Saleous, N. LEDAPS Surface Reflectance Product Description; University of Maryland: College Park, MD, USA, 2007.

50. Vuolo, F.; Mattiuzzi, M.; Atzberger, C. Comparison of the Landsat Surface Reflectance Climate Data Record (CDR) and manually atmospherically corrected data in a semi-arid European study area. Int. J. Appl. Earth Obs. Geoinf. 2015, 42, 1-10. [CrossRef]

51. Bezdek, J.C. Pattern Recognition with Fuzzy Objective Function Algorithms; Plenum Press: New York, NY, USA, 1981.

52. Hwang, C.; Rhee, F.C.H. Uncertain fuzzy clustering: Interval Type-2 fuzzy approach to C-means. IEEE Trans. Fuzzy Syst. 2007, 15, 107-120. [CrossRef]

53. Karnik, N.N.; Mendel, J.M. Centroid of a type-2 fuzzy set. Inf. Sci. 2001, 132, 195-220. [CrossRef]

54. Zarinbal, M.; Zarandi, M.F.; Turksen, I.B. Interval Type-2 Relative Entropy Fuzzy C-Means clustering. Inf. Sci. 2014, 272, 49-72. [CrossRef]

55. Min, J.; Shim, E.A.; Rhee, F.C.H. An interval type-2 fuzzy PCM algorithm for pattern recognition. In Proceedings of the 18th International Conference on Fuzzy Systems (Fuzz-IEEE '09), Jeju Island, South Korea, 20-24 August 2009; pp. 480-483.

56. Ji, Z.; Xia, Y.; Sun, Q.; Cao, G. Interval-valued possibilistic fuzzy C-means clustering algorithm. Fuzzy Sets Syst. 2014, 253, 138-156. [CrossRef]

57. Ondrej, L.; Milos, M. General Type-2 fuzzy C-Means algorithm for uncertain fuzzy clustering. IEEE Trans. Fuzzy Syst. 2012, 20, 883-897.

58. Swain, P.H.; Davis, S.M. Remote Sensing: The Quantitative Approach; McGraw-Hill: New York, NY, USA, 1978.

59. Cheng, J.; Guo, H.; Shi, W. Uncertainty of Remote Sensing Data; Chinese Science Press: Beijing, China, 2004.

60. Shi, W. Principles of Modeling Uncertainties in Spatial Data and Spatial Analyses; CRC Press: Boca Raton, FL, USA, 2009.

61. Huang, J.; Wang, X.; Wang, F. Uncertainty in Padday Rice Remote Sensing; Zhejiang University Press: Hangzhou, China, 2013.

62. Wang, Q.; Shi, W. Unsupervised classification based on fuzzy c-means with uncertainty analysis. Remote Sens. Lett. 2013, 4, 1087-1096. [CrossRef]

63. Yu, X.; He, H.; Hu, D.; Zhou, W. Land cover classification of remote sensing imagery based on interval-valued data fuzzy c-means algorithm. Sci. China Earth Sci. 2014, 57, 1306-1313. [CrossRef]

64. Li, X.; Zhang, S. Rank of interval numbers based on a new distance measure. J. Xihua Univ. (Nat. Sci.) 2008, 27, 87-90.

65. Xiao, J.; Zhang, Y.; Fu, C. Comparison between Methods of Interval Number Ranking Based on Possibility. J. Tianjin Univ. 2011, 44, 705-711.

66. Wang, W.; Zhang, Y. On fuzzy cluster validity indices. Fuzzy Sets Syst. 2007, 158, 2095-2117. [CrossRef]

67. Fukuyama, Y.; Sugeno, M. A new method of choosing the number of clusters for the fuzzy C-means method. In Proceedings of the Fifth Fuzzy Systems Symposium, Kobe, Japan, 2-3 June 1989; pp. 247-250.

68. Xie, X.L.; Beni, G. A validity measure for fuzzy clustering. IEEE Trans. Pattern Anal. Mach. Intell. 1991, 13, 841-847. [CrossRef]

69. Li, H.; Zhang, S.; Ding, X.; Zhang, C.; Dale, P. Performance evaluation of cluster validity indices (CVIs) on Multi/Hyperspectral remote sensing datasets. Remote Sens. 2016, 8, 295. [CrossRef]

70. Yuan, F.; Bauer, M.E. Comparison of impervious surface area and normalized difference vegetation index as indicators of surface urban heat island effects in Landsat imagery. Remote Sens. Environ. 2007, 106, 375-386. [CrossRef]

71. Bezdek, J.C.; Ehrlich, R.; Full, W. FCM: The fuzzy c-means clustering algorithm. Comput. Geosci. 1984, 10, 191-203. [CrossRef]

72. Zlinszky, A.; Kania, A. Will it blend? Visualization and accuracy evaluation of high-resolution fuzzy vegetation maps. Int. Arch. Photogramm. Remote Sens. Spat. Inf. Sci. 2016, XLI-B2, 335-343. [CrossRef]

(C) 2017 by the authors. Licensee MDPI, Basel, Switzerland. This article is an open access article distributed under the terms and conditions of the Creative Commons Attribution (CC BY) license (http:/ / creativecommons.org/licenses/by/4.0/). 